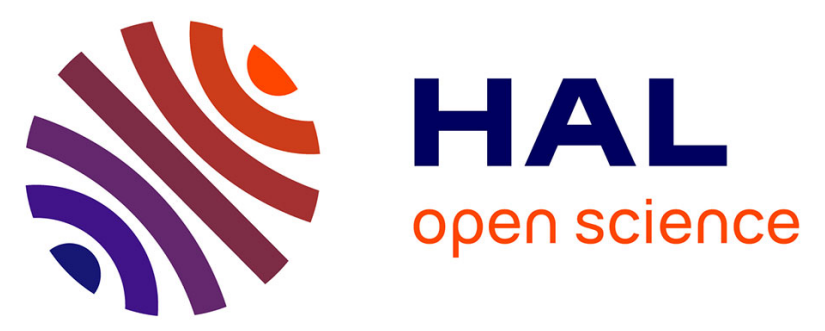

\title{
Interferon- $\gamma$ and Tumor Necrosis Factor- $\alpha$ Produced by T Cells Reduce the HBV Persistence Form, cccDNA, Without Cytolysis
}

Yuchen Xia, Daniela Stadler, Julie Lucifora, Florian Reisinger, Dennis Webb, Marianna Hösel, Thomas Michler, Karin Wisskirchen, Xiaoming Cheng, Ke Zhang, et al.

\section{To cite this version:}

Yuchen Xia, Daniela Stadler, Julie Lucifora, Florian Reisinger, Dennis Webb, et al.. Interferon- $\gamma$ and Tumor Necrosis Factor- $\alpha$ Produced by T Cells Reduce the HBV Persistence Form, cccDNA, Without Cytolysis. Gastroenterology, 2016, 150 (1), pp.194-205. 10.1053/j.gastro.2015.09.026 . hal-01796183

\section{HAL Id: hal-01796183 \\ https://univ-lyon1.hal.science/hal-01796183}

Submitted on 3 Sep 2021

HAL is a multi-disciplinary open access archive for the deposit and dissemination of scientific research documents, whether they are published or not. The documents may come from teaching and research institutions in France or abroad, or from public or private research centers.
L'archive ouverte pluridisciplinaire HAL, est destinée au dépôt et à la diffusion de documents scientifiques de niveau recherche, publiés ou non, émanant des établissements d'enseignement et de recherche français ou étrangers, des laboratoires publics ou privés. 


\section{Accepted Manuscript}

Interferon- $y$ and Tumor Necrosis Factor- $\alpha$ Produced by T Cells Reduce the HBV Persistence Form, cccDNA, Without Cytolysis

Yuchen Xia, Daniela Stadler, Julie Lucifora, Florian Reisinger, Dennis Webb, Marianna Hösel, Thomas Michler, Karin Wisskirchen, Xiaoming Cheng, Ke Zhang, Wen-Min Chou, Jochen M. Wettengel, Antje Malo, Felix Bohne, Dieter Hoffmann, Florian Eyer, Robert Thimme, Christine S. Falk, Wolfgang E. Thasler, Mathias Heikenwalder, Ulrike Protzer
PII: S0016-5085(15)01382-7
DOI: $\quad$ 10.1053/j.gastro.2015.09.026
Reference: $\quad$ YGAST 60047

To appear in: Gastroenterology

Accepted Date: 19 September 2015

Please cite this article as: Xia Y, Stadler D, Lucifora J, Reisinger F, Webb D, Hösel M, Michler T, Wisskirchen K, Cheng X, Zhang K, Chou W-M, Wettengel JM, Malo A, Bohne F, Hoffmann D, Eyer F, Thimme R, Falk CS, Thasler WE, Heikenwalder M, Protzer U, Interferon- $\gamma$ and Tumor Necrosis Factor- $\alpha$ Produced by T Cells Reduce the HBV Persistence Form, cccDNA, Without Cytolysis, Gastroenterology (2015), doi: 10.1053/j.gastro.2015.09.026.

This is a PDF file of an unedited manuscript that has been accepted for publication. As a service to our customers we are providing this early version of the manuscript. The manuscript will undergo copyediting, typesetting, and review of the resulting proof before it is published in its final form. Please note that during the production process errors may be discovered which could affect the content, and all legal disclaimers that apply to the journal pertain. 


\section{Interferon-y and Tumor Necrosis Factor- $\alpha$ Produced by T Cells}

\section{Reduce the HBV Persistence Form, cccDNA, Without Cytolysis}

Yuchen Xia ${ }^{1^{\star} a}$, Daniela Stadler ${ }^{1^{*}}$, Julie Lucifora ${ }^{1,8 b}$, Florian Reisinger $^{1}$, Dennis Webb ${ }^{2}$, Marianna Hösel ${ }^{2,3}$, Thomas Michler ${ }^{1}$, Karin Wisskirchen ${ }^{1}$, Xiaoming Cheng ${ }^{1}$, Ke Zhang ${ }^{1}$,WenMin Chou ${ }^{1}$, Jochen M. Wettengel ${ }^{1}$, Antje Malo ${ }^{1}$, Felix Bohne ${ }^{1}$, Dieter Hoffmann ${ }^{1}$, Florian Eyer $^{4}$, Robert Thimme ${ }^{5}$, Christine S. Falk ${ }^{6,8}$, Wolfgang E.Thasler ${ }^{7}$, Mathias Heikenwalder ${ }^{1}$, Ulrike Protzer ${ }^{1,8}$

${ }^{1}$ Institute of Virology, Technische Universität München / Helmholtz Zentrum München, Trogerstrasse 30, 81675 Munich, Germany

${ }^{2}$ Institute for Medical Microbiology, Immunology and Hygiene, University of Cologne, 50931 Cologne, Germany

${ }^{3}$ Center for Molecular Medicine Cologne, University Hospital Cologne, Robert-Koch-Str. 21, 50931 Cologne, Germany

${ }^{4}$ Medical Clinics II, Department of Clinical Toxicology, University Hospital rechts der Isar, Technische Universität München, Munich, Germany

${ }^{5}$ Department of Medicine II, University Hospital Freiburg, Freiburg, Germany.

${ }^{6}$ Abt Transplantationsimmunologie, Medizinische Hochschule Hannover, Carl-Neuberg Str.1, 30625 Hannover, Germany

${ }^{7}$ Department of General, Visceral, Transplantation, Vascular and Thoracic Surgery, Grosshadern Hospital, Ludwig Maximilians University, 81377 Munich, Germany.

${ }^{8}$ German Center for Infection Research (DZIF), Munich and Hannover sites. *both authors contributed equally to this work.

${ }^{a}$ current address: Liver Diseases Branch, National Institute of Diabetes and Digestive and Kindney Diseases (NIDDK), NIH, 20892 Bethesda, Maryland, USA

${ }^{b}$ current address: INSERM 1052, CNRS UMR 5286, Cancer Research Center of Lyon (CRCL), University of Lyon, 69003 Lyon, France

\section{Grant support}

This study was in part supported by the German Research Foundation (DFG) CRC/TR 36, the German Center for Infection Research (DZIF) and the Helmholtz Association (via the HAI-IDR initiative).

\section{Abbreviations}

3D-PCR, differential DNA denaturation PCR; A3, APOBEC3; ALT, alanine aminotransferase; AP, apurinic/apyrimidinic ; CAR, chimeric antigen receptor; cccDNA, covalently closed 
circular DNA; CTL, cytotoxic T lymphocytes; dHepaRG, differentiated HepaRG; ETV, entecavir; $\mathrm{HBeAg}$, hepatitis $B$ e antigen; HBV, hepatitis B virus; IFN, interferon; LT, lymphotoxin; pgRNA, pregenomic RNA; $\mathrm{PHH}$, primary human hepatocyte; rcDNA, relaxed circular DNA; S-CAR, hepatitis $B$ virus-specific chimeric antigen receptor; TNF, tumor necrosis factor

Short title: T cell derived cytokines diminish HBV cccDNA

Word Count: abstract 260 words, main text 5889 words

\section{Correspondence to:}

Prof. Ulrike Protzer, MD

Institute of Virology, Technische Universität München / Helmholtz Zentrum München

Trogerstr. 30, D-81675 Munich, Germany

Tel: +49-89-41406886, Fax: +49-8941406823

protzer@tum.de; protzer@helmholtz-muenchen.de

\section{Disclosures}

The authors disclose no conflicts of interest.

\section{Author contributions}

YX, DS, MHe and UP designed research; YX, DS, JL, FR, DW, MHö, KW, XC, WMC, JMW, $A M$ and FB conducted research; YX, DS, JL, FR, DW, MHö, TM, and KZ analyzed data; DH, FE, RT, CSF, WET, MHe and UP provided administrative and material support; YX, JL, and UP wrote the paper. All authors read and approved the final manuscript.

\section{Acknowledgments}

We would like to thank Kathrin Kappes, Romina Bester, Theresa Asen, Raindy Tedjukosumo, Martin Feuerherd and Olga Seelbach for their excellent technical support, and Oliver Quitt and Stephanie Kadow for characterization of Huh7-S and HepG2-H1.3 cell lines, respectively. We thank Christoph Seeger for providing cell line HepAD38 and Achim Weber for support with tissue stainings. We acknowledge the support of the non-profit foundation HTCR, which holds human tissue on trust, making it broadly available for research on an ethical and legal basis. 


\section{Abstract}

Background \& Aims: Viral clearance involves immune cell cytolysis of infected cells. However, studies of hepatitis B virus (HBV) infection in chimpanzees have indicated that cytokines released by $\mathrm{T}$ cells can also promote viral clearance via non-cytolytic processes. We investigated the non-cytolytic mechanisms by which T cells eliminate HBV from infected hepatocytes.

Methods: We performed cytokine ELISA of serum samples from patients with acute and chronic hepatitis B. Liver biopsies were analyzed by in situ hybridization. HepG2-H1.3 cells, HBV-infected HepaRG cells, and primary human hepatocytes were incubated with interferonY (IFNY) or tumor necrosis factor- $\alpha$ (TNFa), or co-cultured with $T$ cells. We measured markers of HBV replication, including the covalently closed circular DNA (cccDNA).

Result: Levels of IFNy and TNFa were increased in serum samples from patients with acute vs chronic hepatitis B and controls. In human hepatocytes with stably replicating HBV, as well as in HBV-infected primary human hepatocytes or HepaRG cells, IFNy and TNFa each induced deamination of cccDNA and interfered with its stability; their effects were additive. HBV-specific T cells, through secretion of IFNy and TNFa, inhibited HBV replication and reduced cccDNA in infected cells without the direct contact required for cytolysis. Blocking IFNy and TNF $\alpha$ after T-cell stimulation prevented the loss of cccDNA. Deprivation of cccDNA required activation of nuclear APOBEC3 deaminases by the cytokines. In liver biopsies from patients with acute hepatitis $B$, but not chronic hepatitis $B$ or controls, hepatocytes expressed APOBEC3A and APOBEC3B.

Conclusion: IFNY and TNFa, produced by $\mathrm{T}$ cells, reduce levels of HBV cccDNA in hepatocytes by inducing deamination and subsequent cccDNA decay.

Key words: apolipoprotein B mRNA editing enzyme; HBV persistence; T-cell receptor; immune regulation 


\section{Introduction}

Hepatitis B Virus (HBV) is a small, enveloped DNA virus replicating via an RNA intermediate. After infection, which is hepatocyte specific, the capsid is transported to the nucleus, where the relaxed circular DNA (rcDNA) is released and converted into a covalently closed circular DNA (cccDNA) persistence form. This cccDNA serves as a template for transcription of the different viral RNAs. The $3.5 \mathrm{~kb}$ pregenomic RNA (pgRNA) is encapsidated and reverse transcribed into new rcDNA. rcDNA-containing capsids are then either enveloped and released as newly formed virions or redirected towards the nucleus to establish a cccDNA pool. This, together with the long half-life of the cccDNA molecule in the nucleus, ensures HBV persistence in infected cells.

Despite the availability of an effective vaccine, more than 240 million people worldwide are chronically infected with HBV and at high risk of developing severe liver disease including hepatocellular carcinoma causing about 700000 deaths per year. Individuals who resolved the infection during the acute phase show a strong and polyclonal T-cell response, while a weak and exhausted T-cell response cannot control the virus in the liver microenvironment during chronic infection. ${ }^{1}$ Viral clearance during acute HBV infection is mediated by CD4+ and CD8+ cytotoxic T lymphocytes (CTL). T cells kill infected cells, but can also control the virus by secreting antiviral cytokines that inhibit HBV gene expression and replication in a non-cytolytic fashion. ${ }^{2,3}$ On the other hand, TNF- $\alpha$ secreted by T cells can kill virus-infected cells. ${ }^{4,5}$ Studies using virus-specific CD8+ CTL in vitro, confirmed that HBV replication is controlled by cytokines ${ }^{6}$ with type I IFNs, IFN- $\gamma$ and TNF- $\alpha$ being key mediators. ${ }^{6}$ Due to the lack of suitable infection models, none of these studies, however, addressed the question whether the nuclear viral transcriptional template, the cccDNA, is affected.

The persistence of cccDNA is a crucial issue in virus control since clearance of HBV requires the elimination of cccDNA to prevent reactivation of viral replication and relapse of infection. Studies in HBV-infected chimpanzees ${ }^{7,8}$, which unlike mice establish cccDNA, revealed a loss of cccDNA, when IFN-y-producing CD8+ CTL infiltrated the liver but before an elevation 
of liver enzymes in the serum and a loss of antigen-positive hepatocytes indicated hepatocyte killing by cytotoxic activity. ${ }^{7-9}$ This indicated a two-step process of HBV elimination by CTL: an early non-cytolytic reduction of the cccDNA pool followed by a subsequent direct killing of infected hepatocytes ${ }^{7,8}$ and accompanied by a loss of cccDNA by cell division. ${ }^{10}$ These studies suggested that in addition to transcriptional suppression ${ }^{11}$ cccDNA is susceptible to non-cytolytic clearance by antiviral cytokines.

We have recently reported that cccDNA can be degraded in a specific and non-hepatotoxic fashion, ${ }^{12}$ but how T cells influence this cccDNA fate has remained unknown. The aim of the present study was to address the cellular and molecular mechanisms of non-cytolytic clearance of HBV infection by $\mathrm{T}$ cells via $\mathrm{T}$ cell derived antiviral cytokines using in vitro models of HBV infection that establish a nuclear HBV cccDNA pool and set up co-culture models with HBV-directed primary T cells.

\section{Materials and Methods}

Human samples. Serum samples of 8 acute, 11 chronic hepatitis B patients, 3 healthy subjects and one fulminant, acute hepatitis B patient were collected and fulminant hepatitis B and non-hepatitis control liver biopsies were obtained from University Hospital rechts der Isar. Use of human samples was approved by the local ethics committee. For detection of IFN- $\gamma$ and TNF- $\alpha$ from human serum or cell culture supernatant, human IFN- $\gamma$ MAX ${ }^{\mathrm{TM}}$ (430103, Biolegend) and human TNF ELISA (555212, BD OptEIA ${ }^{\mathrm{TM}}$ ) were used according to the manufacturer's instructions.

Cell cultures. HepaRG cell culture, differentiation was performed as described previously. ${ }^{13}$ Primary human hepatocytes $(\mathrm{PHH})$ were isolated from surgical liver specimens obtained during partial hepatectomy. Tissue samples and annotated data were obtained and experimental procedures were performed within the framework of the non-profit foundation Human Tissue \& Cell Research (HTCR), including the informed patient's consent. ${ }^{14}$ 
cccDNA modification. For differential DNA denaturation PCR (3D-PCR), PCR products from cccDNA-selective qPCR were diluted 1/50 and used as template for nested PCR using primers HBxinfw and HBxinrev at different denaturation temperatures, and analysed by agarose gel electrophoresis ${ }^{12}$. For sequencing, PCR products were purified by gel extraction, cloned using the "TA Cloning® Kit" (Invitrogen). For APE1 digestion, $1 \mu \mathrm{g}$ of total cellular DNA was digested with $10 \mathrm{U}$ APE1 (New England Biolabs) at $3^{\circ} \mathrm{C}$ for 2 hours.

T cell co-culture experiments. $1 \times 10^{6}$ S-CAR- or TCR-grafted T cells (Supplementary Methods) were either co-cultured with HBV infected HepaRG cells or separated using the Transwell ${ }^{\mathrm{TM}}$ culture system $(0.4 \mu \mathrm{m}$, Corning, Amsterdam, Netherlands). Transwells were coated for 2 hours with $5 \mu \mathrm{g} / \mathrm{ml}$ recombinant $\mathrm{HBsAg}$ at $37^{\circ} \mathrm{C}$ or with $1 \times 10^{5} \mathrm{~T}_{2}$ cells incubated with $1 \mu \mathrm{M}$ HBV Peptide $\mathrm{C}_{18-27}$ for 2 hours at $37^{\circ} \mathrm{C}$ or Huh7-S cells. For blocking c ytokines, 20 $\mu \mathrm{g} / \mathrm{ml}$ anti-human IFN- $\mathrm{\gamma}$ (Biolegend, San Diego, CA, USA) and $500 \mathrm{ng} / \mathrm{ml}$ TNF- $\alpha$ neutralizing antibody (Cell Signaling, Danvers, MA, USA) were applied. To block lymphotoxin (LT) $\alpha 1 \beta 2$, LT $\alpha 2 \beta 1$, LT $\alpha 3$ and TNF- $\alpha$ signaling, $5 \mu \mathrm{g} / \mathrm{ml}$ of recombinant $\mathrm{LT} \beta$ receptor-Fc fusion protein (Baminercept, Biogen Idec, Boston, MA, USA) or $10 \mu \mathrm{g} / \mathrm{ml}$ of a recombinant TNF receptor p75-Fc fusion protein (Etanercept/Enbrel, Immunex, Seattle) were used, respectively. Alanine aminotransferase (ALT) was measured with Reflovet Plus system (Roche).

Statistical analysis. Mann-Whitney $U$ tests and Student's unpaired two-tailed t test were performed using Prism 5.0a (GraphPad, La Jolla, CA, USA). Data are shown as mean \pm SD Two-sided $P$ values $<.05$ were considered significant. ${ }^{\star} P<.05,{ }^{* \star} P<.01,{ }^{* \star \star} P<.001$.

\section{Results}

\section{Acute hepatitis B patients have elevated serum IFN-y and TNF- $\alpha$ levels}

It has been suggested that cytokines, particularly IFN- $\gamma$ and TNF- $\alpha$, are involved in the clearance of $\mathrm{HBV}$ in acute, self-limiting hepatitis B in animal models. ${ }^{2,} 7,8$ To investigate whether serum cytokine profiles differ between hepatitis B patients and healthy donors, we 
collected serum from patients of similar demographic background with acute $(n=9)$ or chronic hepatitis B infections $(n=11)$ (Table S2). Both groups had similar HBV-DNA levels, but as expected patients with acute hepatitis B had higher ALT, aspartate aminotransferase and bilirubin levels. Serum IFN-y and TNF- $\alpha$ levels were quantified by ELISA and Luminex assay and compared to healthy controls, and both were significantly elevated in acute hepatitis B (Figure 1).

IFN-Y inhibits HBV replication and nuclear HBV cccDNA accumulation in HepG2-H1.3 cells

Since in particular IFN-y has been proposed to contribute to reduction of cccDNA before final clearance by $\mathrm{T}$ cell killing, ${ }^{7,8}$ we aimed at studying the mechanism of non-cytolytic cccDNA clearance in molecular detail. For this, we first used HBV-replicating cell line HepG2-H1.3, which was generated by stable transfection of HepG2 cells with a single copy 1.3-fold over length HBV genome (Figure $\mathrm{S} 1 \mathrm{~A}, \mathrm{~B})^{15}$ and proved sensitive to treatment with IFN- $\gamma$ as confirmed by up-regulation of the IFN- $\gamma$ induced protein 10 (IP10) mRNA (Figure 2A). Southern blot analysis of low-molecular weight DNA after diminishing protein-bound HBV replicative intermediates ${ }^{8}$ showed the establishment of cccDNA in these cells (Figure S1C). On day 4 and 6, progeny HBV secretion was largely reduced in IFN- $\gamma$ treated cells (Figure 2B). Southern blot analysis revealed that in IFN- $\gamma$ treated cells cytoplasmic HBV capsid contained $60-70 \%$ less HBV-DNA (Figure 2C) and accumulation of cccDNA was inhibited (Figure 2D). This indicated that IFN- $\gamma$-induced intracellular pathways hinder maturation of rcDNA containing HBV capsids, but also reduce nuclear HBV cccDNA either by (i) preventing reimported capsids to establish and restore cccDNA, or by (ii) directly influencing the stability of cccDNA.

cccDNA detection and quantification 
To clarify whether IFN- $\gamma$ directly affects cccDNA stability and whether TNF- $\alpha$ has similar effects, we changed the experimental model to HBV-infected differentiated HepaRG cells (dHepaRG) which establish cccDNA only from incoming HBV and do not divide anymore. ${ }^{16}$ To allow sensitive and reliable quantification of cccDNA, we used a qPCR assay that was designed to specifically detect cccDNA. It uses primers spanning the gap and the nick in rcDNA molecules preventing their amplification and a very rapid cycling protocol that significantly reduces the chance of closing the gap during the elongation step. ${ }^{17,18}$ Using this cccDNA qPCR, hepatitis B patient sera with $3 \times 10^{7} \mathrm{IU} / \mathrm{ml}$ HBV-DNA were positive for HBVDNA but negative for cccDNA-specific qPCR, as were DNA samples from livers of HBVtransgenic mice, which contain high amounts of rcDNA but do not establish cccDNA (Figure S2A). Thus, the specificity of the qPCR assay for cccDNA over rcDNA was confirmed to be $\geq 5 \times 10^{3}$ as reported before. ${ }^{18}$ Treatment of HBV-infected dHepaRG cells with nucleoside analogues such as lamivudine (LAM) or entecavir (ETV) strongly reduced intracellular HBVDNA without affecting the quantification of cccDNA by qPCR (Figure $3 \mathrm{~A})$. To further confirm specificity of cccDNA qPCR, we spiked cccDNA isolated from nuclei of ETV treated HBVinfected cells (which should not contain rcDNA) with rcDNA isolated from patient serum in increasing amounts (Figure 3B,C). Despite the presence of $\geq 10^{4}$ molecules of rcDNA, cccDNA qPCR was still able to detect a proportional decrease of cccDNA (Figure 3B), and a mixture of both DNAs containing a fixed amount of cccDNA with increased amount of rcDNA resulted in negligible Cp value change $( \pm 0.1)$ (Figure $3 \mathrm{C})$.

\section{IFN- $\gamma$ and TNF- $\alpha$ affect cccDNA stability}

To assess the effect of IFN- $\gamma$ and TNF- $\alpha$ on HBV cccDNA, dHepaRG cells that don't divide anymore were infected with HBV and treated after 8 days, when HBV cccDNA had been established. After seven days of treatment with IFN- $\gamma$, intracellular HBV DNA and HBeAg, but also HBV cccDNA (Figure S2B) were reduced in a dose-dependent manner with an $\mathrm{EC}_{90}$ of $200 \mathrm{IU} / \mathrm{ml}$. The effect did not depend on the time point when treatment was started but on 
duration of treatment (Figure S2C). Similar to IFN- $\gamma$, TNF- $\alpha$ reduced total HBV intracellular DNA and HBeAg, but more importantly also cccDNA in a dose dependent manner with an $\mathrm{EC}_{90}$ of $800 \mathrm{IU} / \mathrm{ml}$ (Figure S2D).

Since HBV infected PHH are still the golden standard for HBV infection studies in vitro and most closely resemble the in vivo situation, we infected $\mathrm{PHH}$ isolated from different donors with HBV for 10 days, and then initiated treatment with $200 \mathrm{IU} / \mathrm{ml} \mathrm{IFN}-\gamma$ or $800 \mathrm{IU} / \mathrm{ml}$ TNF- $\alpha$ for 7 days (Figure 3D,E). Although the responses varied from donor to donor, in all infection experiments cccDNA and HBeAg declined upon IFN- $\gamma$ and upon TNF- $\alpha$ treatment.

To confirm that our treatment affected established cccDNA and not rcDNA in the cytoplasm, which may then be reimported into the nucleus, we pre-treated HBV infected dHepaRG cells with high dose of ETV $\left(0.5 \mu \mathrm{M}, 100\right.$-fold $\left.\mathrm{IC}_{90}\right)$ to block HBV rcDNA formation before initiating IFN- $\gamma$ or TNF- $\alpha$ treatment. As expected, ETV did neither affect HBV cccDNA nor HBeAg, but strongly reduced total intracellular HBV-DNA, which is mainly HBV rcDNA (Figure 3F). Importantly, ETV pretreatment did not affect cccDNA loss upon IFN- $\gamma$ or TNF- $\alpha$ treatment demonstrating that IFN- $\gamma$ and TNF- $\alpha$ induced pathways indeed target established, nuclear cccDNA (Figure 3F). To exclude that cccDNA loss was caused by pro-apoptotic or cytotoxic effects of IFN- $\gamma$ or TNF- $\alpha$ or by cell division, ${ }^{10,19}$ we performed XTT assay and evaluated total cellular mitochondrial DNA by qPCR. Treatment of HBV-infected dHepaRG with up to 4000 $\mathrm{IU} / \mathrm{ml}$ of IFN- $\gamma$ (Figure S3A) or $1600 \mathrm{IU} / \mathrm{ml}$ TNF- $\alpha$ (Figure S3B) did neither affect cell viability or metabolic capacity, nor did it induce mitochondrial damage in HepaRG or PHH (Figure $\mathrm{S} 3 \mathrm{C}$ ), activate caspase-3 cleavage (Figure S3D) or lead to lactate dehydrogenase release although HBV was inhibited (Figure S3E). Treating dHepaRG-pEpi-H1.3 cells ${ }^{12}$ that establish cccDNA in addition to episomal pEpi-H1.3 plasmid DNA resulted in a selective loss of HBV cccDNA (Figure S3F). Taken together, these results strongly suggested a direct effect of IFN- $\gamma$ and TNF- $\alpha$ on HBV cccDNA.

\section{IFN- $\gamma$ and TNF- $\alpha$ induce cccDNA deamination and decay}


We recently described that either IFN- $\alpha$ treatment or LT $\beta$ R-activation lead to cccDNA degradation in infected hepatocytes by introducing deamination in cccDNA through the activity of $A$ POBEC3A (A3A) or APOBEC3B (A3B), respectively. ${ }^{12}$ In order to test if similar mechanisms would be involved in IFN- $\gamma$ or TNF- $\alpha$ induced cccDNA decay, we first investigated cccDNA deamination by 3D-PCR, which detects mutants with GC to AT transitions due to their lower denaturation temperature. ${ }^{20}$ At low denaturing temperatures $\left(83 / 84^{\circ} \mathrm{C}\right)$ we amplified only cccDNA from HBV infecte d dHepaRG cells treated with IFN- $\gamma$ (Figure 4A) or TNF- $\alpha$ (Figure 4B). Sequence analysis revealed increased $G$ to $A$ transition (Figure S4A,B; 4C,D) and thus deamination of the cccDNA minus strand. ${ }^{12}$ To confirm that 3D-PCR detected deamination in cccDNA and not in rcDNA, we pre-treated HBV-infected dHepaRG cells with $0.5 \mu \mathrm{M}$ ETV for two days to inhibit rcDNA formation. IFN- $\gamma$ and TNF- $\alpha$ induced the same cccDNA modification as without ETV treatment while ETV alone did not affect cccDNA characteristics (Figure S4C).

The consequence of DNA deamination is uracil-DNA glycosylase cleavage of uracils to form apurinic/apyrimidinic (AP) sites. $^{21} \mathrm{AP}$ sites are then recognized and cleaved by AP endonuclease such as APE1. To investigate whether cccDNA contains AP sites, we extracted DNA from IFN- $\gamma$ or TNF- $\alpha$ treated cells, incubated it with recombinant APE1 and quantified remaining cccDNA by qPCR. Reduced cccDNA in DNA extracted from IFN- $\gamma$ and TNF- $\alpha$ treated, but not from mock treated dHepaRG cells (Figure 4E) and PHH (Figure 4F) confirmed the presence of AP sites. Knock down of APE1 resulted in elevated cccDNA levels in mock treated cells indicating a contribution of APE1 to cccDNA control (Figure S4D,E). Knock-down of APE1, however, resulted in comparable cccDNA decay pattern upon IFN- $\gamma$ or TNF- $\alpha$ treatment indicating that other endonucleases may compensate for APE1 deficiency (Figure S4E). Taken together, both IFN- $\gamma$ and TNF- $\alpha$ treatment induced deamination and APsite formation in HBV cccDNA, which is recognized and digested by endonuclease. 


\section{APOBEC3A and APOBEC3B activity is essential to induce deamination and deprivation of $\mathrm{HBV}$ cccDNA}

We previously reported that $A 3 \mathrm{~A}$ and $\mathrm{A} 3 \mathrm{~B}$ are essential in IFN- $\alpha$ or LT $\beta R$-agonist treatment respectively. ${ }^{12}$ To test whether these two proteins may be involved in viral clearance during the acute phase of hepatitis $B, A 3 A$ and $A 3 B$ mRNA expression was analysed in patient liver biopsies by in situ hybridization. Positive signals of both mRNAs were clearly detected in hepatocytes in biopsies of patients with fulminant and acute hepatitis $B$, but not with chronic hepatitis $B$ or in biopsies of patients after metastasis resection negative for hepatitis $B$ or $C$ (Figure 5A).

To examine the role of these two deaminases in IFN- $\gamma$ and TNF- $\alpha$ induced $\operatorname{cccDNA}$ deamination and decay, A3A and A3B were knocked down in HBV infected HepaRG cells. Quantification of A3A and A3B mRNA by qPCR revealed that after $24 \mathrm{~h}$ A3A was induced by IFN- $\gamma$, but not by TNF- $\alpha$. A3B was upregulated by both IFN- $\gamma$ and TNF- $\alpha$ (Figure 5B). Transfection of siRNA targeting $\mathrm{A} 3 \mathrm{~A}$ and $\mathrm{A} 3 \mathrm{~B}$ reduced mRNAs of these two genes by $90 \%$ and $80 \%$, respectively (Figure $5 \mathrm{~B}$ ), and deamination of $\operatorname{cccDNA}$ induced by IFN- $\gamma$ or TNF- $\alpha$ was almost completely inhibited (Figure 5C). Importantly, cccDNA levels under IFN- $\gamma$ as well as TNF- $\alpha$ treatment significantly increased when A3A and A3B were knocked down, while HBeAg levels only slightly changed (Figure 5D). Taken together, nuclear deaminases A3A and A3B are upregulated in hepatocytes during acute hepatitis B and upon IFN- $\gamma$ and TNF- $\alpha$ treatment and are essential for deamination and decay of HBV cccDNA at least in our cell culture model.

\section{T cells have the ability to diminish HBV cccDNA in a non-cytolytic fashion}

Since $\mathrm{T}$ cells are considered an important source for IFN- $\gamma$ and TNF- $\alpha$, we next asked whether $\mathrm{T}$ cells could induce non-cytolytic cccDNA deprivation by secretion of these two cytokines. We have previously shown that $\mathrm{T}$ cells expressing a chimeric antigen receptor 
recognize HBV envelope proteins (S-CAR) on the surface of infected cells and control HBV replication in vitro and in vivo. ${ }^{22,23}$ To distinguish the non-cytolytic effect on HBV cccDNA from T cell-mediated direct killing of infected hepatocytes, we established co-cultures of SCAR grafted T cells and HBV-infected dHepaRG cells - either in direct contact or separated by a transwell. The transwell system permitted cultivation of $\mathrm{T}$ cells with and without stimulation, and prevented direct killing of HBV-infected cells, but allowed cytokines produced to pass through the membrane and reach the HBV-infected cells (Figure 6A). ALT released into cell culture medium by damaged hepatocytes indicated that HBV infected dHepaRG cells died only when directly co-cultured with S-CAR-grafted T cells (Figure 6B). The cytokine secretion profile of T cells was determined by human cytokine array (Figure S5). As expected, activated T cells secreted a number of cytokines including regulatory cytokines like IL-5, IL-13, CCL1 (I-309) and GM-CSF as well as antiviral cytokines like IFN- $\gamma$ and TNF$\alpha$. The amount of secreted IFN- $\gamma$ and TNF- $\alpha$ was highest when T cells were activated by coating the transwell with HBsAg (Figure 6C). In contrast, barely any cytokine secretion from T cells was detected without activation. cccDNA as well as $\mathrm{HBeAg}$ were largely diminished if cytolytic activity of $\mathrm{T}$ cells was permitted by co-culture of T cells and infected dHepaRG cells (Figure 6D). More importantly, combined IFN- $\gamma$ and TNF- $\alpha$ treatment and cytokine secretion after stimulation of S-CAR grafted T cells in the transwell resulted in significantly reduced HBV cccDNA and HBeAg levels (Figure 6D). When S-CAR-grafted T cells were activated more physiologically with Huh7 cells expressing HBsAg, they also secreted IFN- $\gamma$ and TNF- $\alpha$ that had induced cccDNA decay when transwells with $\mathrm{T}$ cells and cytokines were removed after 2 days (Figure S6A,B). Hereby, cccDNA deamination reflected the induction of A3A and A3B by $T$ cell cytokines either after direct contact with infected cells or after stimulation in the transwell (Figure 6E). The same was observed when $\mathrm{T}$ cells were grafted with an HBV core $_{18-27}$-specific $\mathrm{T}$ cell receptor (TCR) and activated in a transwell by $\mathrm{T} 2$ cells presenting HBV peptide core ${ }_{18-27}$ (Figure S6C-E). This argued for a universal non-cytolytic antiviral activity of $T$ cells that is able to induce the decay of HBV cccDNA. 


\section{IFN- $\gamma$ and TNF- $\alpha$ are responsible for the non-cytolytic antiviral activity of T-cells in an} additive fashion

To analyse if IFN- $\gamma$ and TNF- $\alpha$ work in an additive or even synergistic fashion, HBV infected dHepaRG cells and PHH were treated with $200 \mathrm{IU} / \mathrm{ml} \mathrm{IFN}-\gamma, 800 \mathrm{IU} / \mathrm{ml}$ TNF- $\alpha$ or a combination of both for 7 days. The combination of IFN- $\gamma$ and TNF- $\alpha$ increased cccDNA decay in an additive fashion, decreased the cccDNA denaturation temperature in 3D-PCR, induced more $\mathrm{G}$ to $\mathrm{A}$ transitions (Figure S7A-D). Furthermore, combining IFN- $\gamma$ and TNF- $\alpha$ led to faster, stronger, and most importantly to more sustained induction of $A 3 A$ and $A 3 B$ expression (Figure S7E).

To investigate the physiological significance of this antiviral mechanism, we asked how fast the T cells could be activated and induce cccDNA loss. S-CAR T cells stimulated with Huh7 or Huh7-S cells started to produce IFN- $\gamma$ and TNF- $\alpha$ after 16 hours (Figure 7A,B) in accordance with the fact that antigen contact for about 20 hours is necessary to convert $T$ cells into effector cells ${ }^{24}$. When transferred onto HBV-infected dHepaRG cells, a 12 hours' incubation with the cytokine secreting $T$ cells was sufficient to induce cccDNA loss (Figure $7 \mathrm{C})$, which was maximal after a $24 \mathrm{~h}$ incubation period coinciding with $\mathrm{HBeAg}$ declining that happened at slower kinetics (Figure 7D).

To study which cytokines mediate the non-cytolytic antiviral activity of $\mathrm{T}$ cells, neutralizing antibodies were applied in the transwell co-culture system. IFN- $\gamma$ neutralizing antibodies rescued about $2 / 3$ of cccDNA loss, while TNF- $\alpha$ neutralizing antibodies had a minor but still significant effect. The combination of the two neutralizing antibodies restored HBV cccDNA as well as $\mathrm{HBeAg}$ to $>80 \%$ (Figure 7E). Notably, additional blockade of lymphotoxin $\beta$ receptor signalling did not further rescue $\mathrm{HBV}$ in the transwell setting (Figure 7F). These experiments confirmed that IFN- $\gamma$ and TNF- $\alpha$ are the key factors in non-cytolytic inhibition of HBV by T cells, and most importantly that these cytokines are able to trigger nuclear HBV- 
DNA degradation in an additive fashion with IFN- $\gamma$ playing the dominant role. We thus concluded that $T$ cells lead to cccDNA elimination in a cytolytic, but also in a non-cytolytic fashion via cytokine secretion.

\section{Discussion}

Clearance of HBV infection by the immune system seems to require killing of infected cells by virus specific CTL. To which extend and by which mechanisms non-cytolytic $T$ cell function contributes to virus clearance has not been defined yet. This study demonstrates that $\mathrm{T}$ cells can induce the loss of HBV cccDNA in HBV-infected, differentiated hepatocytes mainly through secretion of the cytokines IFN- $\gamma$ and TNF- $\alpha$, which induce A3A and A3B that play an essential role in deamination of nuclear HBV-DNA and subsequent deprivation. Thus, T-cell derived cytokines not only control HBV replication at a post-transcriptional level ${ }^{6}$ and by transcriptional suppression ${ }^{11}$, but also induce deamination, subsequent AP site formation and degradation of the viral persistence form in infected hepatocytes.

Our observation that IFN- $\gamma$ and TNF- $\alpha$ levels are higher in acute hepatitis B patient serum compared to chronic patients or healthy donors confirms former publications. ${ }^{25}$ Between chronic hepatitis B patients and healthy individuals who recovered from HBV infection a significant difference in the distribution of the IFN- $\gamma$ gene polymorphism has been described. ${ }^{26}$ In addition, a polymorphism at position -183 of the IFN- $\gamma$ gene promoter seems to be associated with susceptibility to HBV infection. ${ }^{27}$ Accordingly, TNF- $\alpha$ promoter polymorphisms ${ }^{28}$ as well as the TNF- $\alpha 238-\mathrm{A}$ allele ${ }^{29}$ may affect clearance of HBV infection. These studies as well as experience with anti-TNF therapies ${ }^{30}$ and the fact that HBV counteracts TNF- $\alpha$ effects emphasize the clinical importance of IFN- $\gamma$ and TNF- $\alpha{ }^{19}$ in control and clearance of HBV infection.

In acute HBV infection, infiltration of IFN- $\gamma$ positive $\mathrm{T}$ cells seemed to affect the cccDNA content in livers of HBV-infected chimpanzees, but the molecular mechanism by which 
cccDNA could be affected remained unknown. ${ }^{7,9}$ IFN- $\gamma$ and TNF- $\alpha$ can affect HBV replication by different mechanisms and were reported to act synergistically. ${ }^{31,}{ }^{32} \mathrm{IFN}-\gamma$ interacts with HBV capsid formation ${ }^{33}$, eliminates pgRNA containing capsid ${ }^{34}$ and selectively accelerates the decay of replication-competent HBV capsids. ${ }^{35}$ TNF- $\alpha$ inhibits HBV replication by disrupting capsid integrity. ${ }^{36}$ Here we show that IFN- $\gamma$ prevents the refill of cccDNA by affecting the formation of rcDNA containing capsids - and in addition destabilizes HBV cccDNA. To be able to draw this conclusion and to minimize cccDNA loss by cell division ${ }^{10}$, we have focussed on using HBV-infected dHepaRG cells or $\mathrm{PHH}$, which establish a very stable pool of cccDNA molecules by conversion of the rcDNA from incoming virus, but show little cccDNA amplification. ${ }^{16}$ Pre-treatment with reverse transcriptase inhibitors inhibiting rcDNA formation confirmed the targeting of established nuclear HBV-DNA, and siRNA knock-down experiments of $\mathrm{A} 3 \mathrm{~A}$ and $\mathrm{A} 3 \mathrm{~B}$ excluded that cccDNA was merely lost by cell division. Interestingly, cccDNA levels raised already after A3A and A3B knock-down in mock treated cells. This indicates a background activity in HBV infected cells modifying cccDNA even in the absence of any treatment.

APOBEC3 expression patterns vary in different human tissues. However, they can be induced by IFN- $\alpha$, IFN- - , TNF- $\alpha$, lymphotoxin $\beta$ receptor activation, poly (I:C) or LPS through different signalling pathways. ${ }^{12,37,38}$ We here show that nuclear A3A and A3B expression is activated in hepatocytes during acute hepatitis B. Blocking IFN- $\gamma$ and TNF- $\alpha$ resulted in $80 \%$ recovery of non-cytolytic cccDNA loss. This indicated that other cytokines might also be involved, although we were not able to pinpoint them. The same holds true for immune cells other than T cells. NK cells and NKT cells for example may also play an important role in non-cytolytic viral clearance by secreting IFN- $\gamma^{7,8}$

Our experiments cannot give a final proof that non-cytolytic antivral effects of $T$ cells play a role. There are, however, strong arguments for this. First because of the high number of target hepatocytes $\left(10^{11}\right.$ in a human), the number of virus-specific $T$ cells reaching the liver 
seems too low to screen and kill all infected cells at once. While T cells expand, they can already elicit non-cytolytic effects by releasing cytokines. ${ }^{7,8} \mathrm{~T}$ cells have the ability to create a high cytokine concentration in the local microenvironment; the $20 \mathrm{ng}$ IFN- $\gamma$ per $\mathrm{ml}$ we detected is equal to 1200 IU Secondly, especially in the liver one finds a high percentage of partially exhausted T cells that have lost their ability to kill but still secrete IFN- $\gamma^{1}$ Although cccDNA loss involves the regulation of many enzymes and need to take 4-7 days, it only requires a short incubation time with cytokine-secreting $T$ cells. Thus, early during a $T$ cell response, but also in the setting of virus persistence and $T$ cell exhaustion, non-cytolytic cccDNA control may play a role.

Since current treatments for chronic hepatitis B are not satisfying and a cure is hardly achieved, treatment alternatives are sought. In the present study we show that besides direct killing T cells contribute to HBV control and elimination by non-cytolytic functions, namely the release of IFN- $\gamma$ and TNF- $\alpha$, that result in deprivation of HBV cccDNA. This encourages the development of therapies restoring $T$ cell responses in chronic hepatitis $B$, e.g. by therapeutic vaccination, adoptive $\mathrm{T}$ cell therapy, redirection of $\mathrm{T}$ cells or the use of checkpoint inhibitors, to achieve sustained control of HBV infection or even cure of hepatitis B. 


\section{References}

1. Protzer U, Maini MK, Knolle PA. Living in the liver: hepatic infections. Nat Rev Immunol 2012;12:201-13.

2. Guidotti LG, Ando K, Hobbs MV, et al. Cytotoxic T lymphocytes inhibit hepatitis B virus gene expression by a noncytolytic mechanism in transgenic mice. Proc Natl Acad Sci U S A 1994;91:3764-8.

3. McClary H, Koch R, Chisari FV, et al. Relative sensitivity of hepatitis $B$ virus and other hepatotropic viruses to the antiviral effects of cytokines. J Virol 2000;74:2255-64.

4. Wohlleber D, Kashkar H, Gartner K, et al. TNF-induced target cell killing by CTL activated through cross-presentation. Cell Rep 2012;2:478-87.

5. Ebert G, Preston S, Allison C, et al. Cellular inhibitor of apoptosis proteins prevent clearance of hepatitis B virus. Proc Natl Acad Sci U S A 2015.

6. Phillips S, Chokshi S, Riva A, et al. CD8(+) T cell control of hepatitis B virus replication: direct comparison between cytolytic and noncytolytic functions. J Immunol 2010;184:287-95.

7. Guidotti LG, Rochford R, Chung J, et al. Viral clearance without destruction of infected cells during acute HBV infection. Science 1999;284:825-9.

8. Wieland SF, Spangenberg HC, Thimme R, et al. Expansion and contraction of the hepatitis B virus transcriptional template in infected chimpanzees. Proc Natl Acad Sci U S A 2004;101:2129-34.

9. Thimme $R$, Wieland S, Steiger $C$, et al. CD8(+) T cells mediate viral clearance and disease pathogenesis during acute hepatitis B virus infection. J Virol 2003;77:68-76.

10. Summers J, Jilbert $A R$, Yang $W$, et al. Hepatocyte turnover during resolution of a transient hepadnaviral infection. Proc Natl Acad Sci U S A 2003;100:11652-9.

11. Liu F, Campagna M, Qi $Y$, et al. Alpha-interferon suppresses hepadnavirus transcription by altering epigenetic modification of cccDNA minichromosomes. PLoS Pathog 2013;9:e1003613.

12. Lucifora J, Xia $\mathbf{Y}$, Reisinger $F$, et al. Specific and nonhepatotoxic degradation of nuclear hepatitis B virus cccDNA. Science 2014;343:1221-8.

13. Lucifora J, Arzberger S, Durantel D, et al. Hepatitis B virus $X$ protein is essential to initiate and maintain virus replication after infection. J Hepatol 2011;55:996-1003.

14. Thasler WE, Weiss TS, Schillhorn K, et al. Charitable State-Controlled Foundation Human Tissue and Cell Research: Ethic and Legal Aspects in the Supply of Surgically Removed Human Tissue For Research in the Academic and Commercial Sector in Germany. Cell Tissue Bank 2003;4:49-56.

15. Jost $S$, Turelli $P$, Mangeat $B$, et al. Induction of antiviral cytidine deaminases does not explain the inhibition of hepatitis B virus replication by interferons. J Virol 2007;81:10588-96.

16. Hantz $O$, Parent $R$, Durantel $D$, et al. Persistence of the hepatitis B virus covalently closed circular DNA in HepaRG human hepatocyte-like cells. J Gen Virol 2009;90:127-35.

17. Glebe $D$, Aliakbari $M$, Krass $P$, et al. Pre-s1 antigen-dependent infection of Tupaia hepatocyte cultures with human hepatitis B virus. J Virol 2003;77:9511-21.

18. Untergasser A, Zedler U, Langenkamp A, et al. Dendritic cells take up viral antigens but do not support the early steps of hepatitis B virus infection. Hepatology 2006;43:539-47.

19. Ebert $\mathrm{G}$, Allison C, Preston $\mathrm{S}$, et al. Eliminating hepatitis B by antagonizing cellular inhibitors of apoptosis. Proc Natl Acad Sci U S A 2015.

20. Suspene $R$, Guetard D, Henry $M$, et al. Extensive editing of both hepatitis $B$ virus DNA strands by APOBEC3 cytidine deaminases in vitro and in vivo. Proc Natl Acad Sci U S A 2005;102:8321-6.

21. Krokan HE, Bjoras M. Base excision repair. Cold Spring Harb Perspect Biol 2013;5:a012583.

22. Bohne $F, C h m i e l e w s k i ~ M, ~ E b e r t ~ G$, et al. T cells redirected against hepatitis $B$ virus surface proteins eliminate infected hepatocytes. Gastroenterology 2008;134:239-47. 
23. Krebs $\mathbf{K}$, Bottinger $\mathbf{N}$, Huang $L R$, et al. $T$ cells expressing a chimeric antigen receptor that binds hepatitis $B$ virus envelope proteins control virus replication in mice. Gastroenterology 2013;145:456-65.

24. Lanzavecchia A, Sallusto F. Dynamics of T lymphocyte responses: intermediates, effectors, and memory cells. Science 2000;290:92-7.

25. Dimitropoulou D, Karakantza M, Theodorou GL, et al. Serum cytokine profile in patients with hepatitis $B$ e antigen-negative chronic active hepatitis $B$ and inactive hepatitis $B$ virus carriers. World J Gastrointest Pathophysiol 2013;4:24-7.

26. Ben-Ari Z, Mor E, Papo O, et al. Cytokine gene polymorphisms in patients infected with hepatitis B virus. Am J Gastroenterol 2003;98:144-50.

27. Qi S, Cao B, Jiang M, et al. Association of the -183 polymorphism in the IFN-gamma gene promoter with hepatitis B virus infection in the Chinese population. J Clin Lab Anal 2005;19:276-81.

28. Kim YJ, Lee HS, Yoon JH, et al. Association of TNF-alpha promoter polymorphisms with the clearance of hepatitis B virus infection. Hum Mol Genet 2003;12:2541-6.

29. Zheng $\mathrm{MH}$, Xiao DD, Lin XF, et al. The tumour necrosis factor-alpha-238A allele increases the risk of chronic HBV infection in European populations. J Viral Hepat 2012;19:e11-7.

30. Roux $\mathrm{CH}$, Brocq $\mathrm{O}$, Breuil V, et al. Safety of anti-TNF-alpha therapy in rheumatoid arthritis and spondylarthropathies with concurrent B or C chronic hepatitis. Rheumatology (Oxford) 2006;45:1294-7.

31. Feduchi E, Alonso MA, Carrasco L. Human gamma interferon and tumor necrosis factor exert a synergistic blockade on the replication of herpes simplex virus. J Virol 1989;63:1354-9.

32. Lucin $\mathrm{P}$, Jonjic $\mathrm{S}$, Messerle $\mathrm{M}$, et al. Late phase inhibition of murine cytomegalovirus replication by synergistic action of interferon-gamma and tumour necrosis factor. J Gen Virol 1994;75 ( Pt 1):101-10.

33. Wieland SF, Eustaquio A, Whitten-Bauer C, et al. Interferon prevents formation of replication-competent hepatitis B virus RNA-containing nucleocapsids. Proc Natl Acad Sci U S A 2005;102:9913-7.

34. Pasquetto V, Wieland SF, Uprichard SL, et al. Cytokine-sensitive replication of hepatitis B virus in immortalized mouse hepatocyte cultures. J Virol 2002;76:5646-53.

35. Xu C, Guo H, Pan XB, et al. Interferons accelerate decay of replication-competent nucleocapsids of hepatitis B virus. J Virol 2010;84:9332-40.

36. Biermer M, Puro R, Schneider RJ. Tumor necrosis factor alpha inhibition of hepatitis $B$ virus replication involves disruption of capsid Integrity through activation of NF-kappaB. J Virol 2003;77:4033-42.

37. Bonvin $M$, Achermann $F$, Greeve I, et al. Interferon-inducible expression of APOBEC3 editing enzymes in human hepatocytes and inhibition of hepatitis B virus replication. Hepatology 2006;43:1364-74.

38. Mehta HV, Jones PH, Weiss JP, et al. IFN-alpha and lipopolysaccharide upregulate APOBEC3 mRNA through different signaling pathways. J Immunol 2012;189:4088-103.

Author names in bold designate shared co-first authorship. 


\section{Figure Legends}

Figure 1: Serum IFN-y and TNF-a levels. Serum samples from acute or chronic hepatitis B patients, or healthy individuals were collected. IFN- $\gamma$ and TNF- $\alpha$ level were analyzed by ELISA and Luminex assay. Individual values and median of each group are shown. ${ }^{\star} P<0.01$; Mann-Whitney U test.

Figure 2: IFN-Y inhibits HBV replication and cccDNA accumulation in HepG2-H1.3 cells.

(A) HepG2-H1.3 cells were treated daily with 1000 IU/ml IFN-y. Relative IP10 gene expression was determined by real-time RT-PCR, mock-treated samples were set to 1. (B) Cell culture media were analyzed for HBV progeny release by DNA dot blot hybridization. (C) Southern blot analysis of DNA isolated from cytoplasmic HBV capsids. Signal intensities were quantified using a phosphoimager relative to non-treated samples. (D) HepG2-H1.3 cells were seeded at $80 \%$ density and IFN- $\gamma(1000 \mathrm{IU} / \mathrm{ml})$ treatment was started the day after (day 0). Low molecular weight DNA was isolated after spiking with HBV plasmid DNA.

Southern blot analysis detected HBV cccDNA (upper panel), and linearized HBV and plasmid DNA after restriction digest with Xhol (lower panel). Quantification of the cccDNA signal relative to non-treated cells at day 8 is indicated below each lane.

Figure 3: IFN-y or TNF- $\alpha$ treatment interferes with cccDNA stability. (A) HBV infected dHepaRG cells were treated with $0.5 \mu \mathrm{M}$ lamivudine (LAM) or $0.5 \mu \mathrm{M}$ entecavir (ETV) for 3 days. Total HBV-DNA and cccDNA were determined by selective qPCR. (B,C) cccDNA isolated from nuclei of ETV-treated, HBV-infected cells was mixed with rcDNA isolated from patient serum at indicated amounts and (B) quantified by qPCR with cccDNA selective or non-selective HBV-DNA primers. (C) Cp values were determined by cccDNA selective primers. (D) HBV infected PHHs from different donors were treated with $200 \mathrm{IU} / \mathrm{ml}$ IFN- $\mathrm{Y}$ or (E) $800 \mathrm{IU} / \mathrm{ml}$ TNF- $\alpha$ for 7 days. (F) HBV infected dHepaRG cells were treated with $0.5 \mu \mathrm{M}$ ETV alone for 9 days, or pre-treated with ETV for 3 days and then ETV plus $200 \mathrm{IU} / \mathrm{ml}$ IFN-Y 
or $800 \mathrm{IU} / \mathrm{ml}$ TNF- $\alpha$ for another 6 days. HBV cccDNA or total intracellular DNA relative to cellular DNA were analyzed by qPCR, HBeAg was quantified by ELISA. nd: not determined, ns: not significant.

Figure 4: IFN-y or TNF- $\alpha$ treatment induces cccDNA deamination and AP site formation. HBV infected HepaRG cells were treated with $200 \mathrm{IU} / \mathrm{ml}$ IFN-Y (A) or $800 \mathrm{IU} / \mathrm{ml}$ TNF- $\alpha(\mathbf{C})$ for 7 days. 3D-PCR were performed on cccDNA and products positive for the lowest denaturation temperature were cloned and sequenced, and mutations were analyzed (B,D). HBV infected dHepaRG cells (E) or PHHs (F) were treated with $200 \mathrm{IU} / \mathrm{ml}$ IFN-y or $800 \mathrm{IU} / \mathrm{ml}$ TNF- $\alpha$ for 7 days, total DNA extracts were digested with APE1, cccDNA amounts were determined by qPCR.

Figure 5: Reduction of cccDNA depends on APOBEC3A and APOBEC3B activity. (A) $\mathrm{A} 3 \mathrm{~A}$ and $\mathrm{A} 3 \mathrm{~B}$ mRNA from fulminant, acute and chronic hepatitis $\mathrm{B}$ patients or non-hepatitis control liver biopsies were determined by in situ hybridization. HBV infected dHepaRG cells were treated with $200 \mathrm{IU} / \mathrm{ml}$ IFN-ץ or $800 \mathrm{IU} / \mathrm{ml}$ TNF- $\alpha$ and transfected with siRNA against A3A and A3B. (B) Expression of A3A and A3B was analyzed by qRT-PCR. (C) 3D-PCR was performed on cccDNA. (D) HBV cccDNA relative to PRNP was analyzed by qPCR and HBeAg was quantified by ELISA.

Figure 6: Noncytopathic antiviral effect of T cells. (A) HBV infected dHepaRG cells were cultured in lower wells of a transwell culture system without any treatment, treated with IFN-Y and TNF- $\alpha$, co-cultured with S-CAR-grafted T cells, or cultured with S-CAR-grafted T cells that were separated by a transwell with or without HBsAg coating. ALT activity (B) and secreted IFN- $y$ and TNF- $\alpha(\mathbf{C})$ were measured in the cell culture supernatant on indicated days. (D) HBV cccDNA relative to PRNP was analyzed by qPCR and HBeAg was quantified by ELISA. (E) 3D-PCR was performed on cccDNA. 


\section{Figure 7: Loss of HBV cccDNA through T-cell derived IFN- $\gamma$ and TNF- $\alpha$. (A) S-CAR T} cells were activated by Huh7 or Huh7-S cells in a transwell and then transferred within the transwell chamber onto HBV-infected dHepaRG cells. (B) Kinetics of IFN-y and TNF- $\alpha$ secretion determined by ELISA. (C,D) S-CAR T cells, activated for 16 hours, were transferred to the HBV-infected cells (time point 0 ) and left there to elicit their non-cytolytic function for the indicated incubation time. (C) cccDNA in HBV infected dHepaRG cells and (D) $\mathrm{HBeAg}$ secretion were determined at day 7. (E) Neutralizing antibodies (NeuAb) were used to neutralize IFN-y and TNF- $\alpha$, (F) lymphotoxin $\beta$ receptor binding (Baminercept) or LTs and TNF (Etanercept) in the transwell setting. (nd, not detected) 

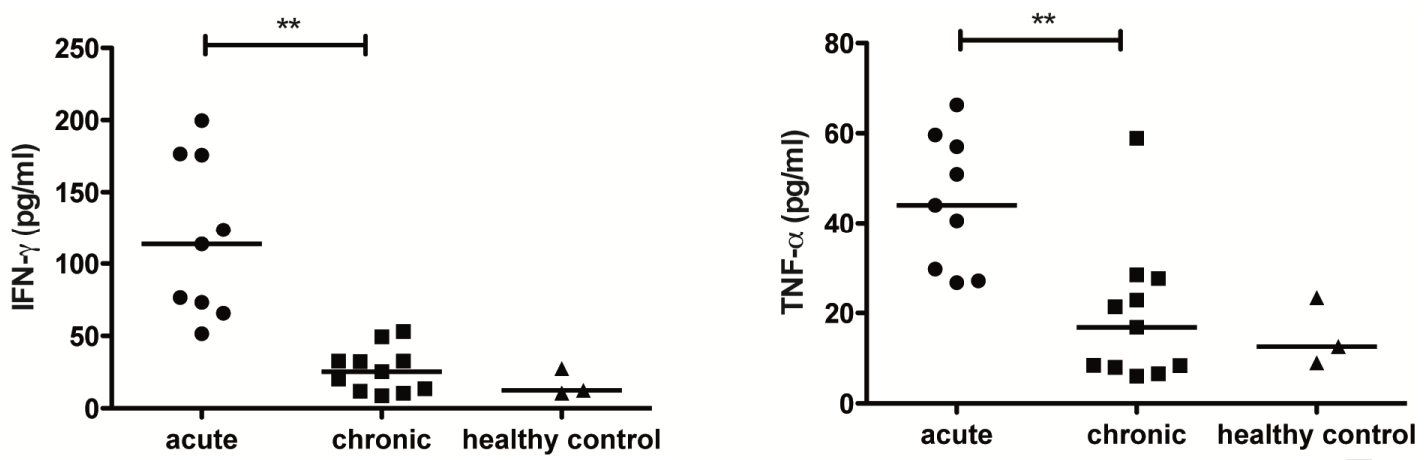
A

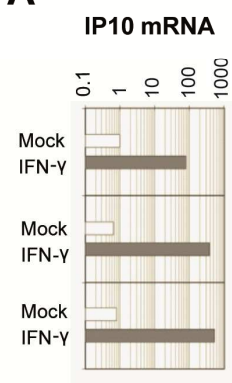

B

HBV progeny

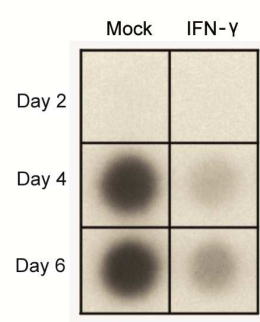

C

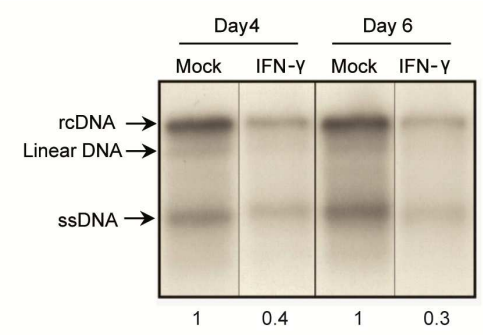

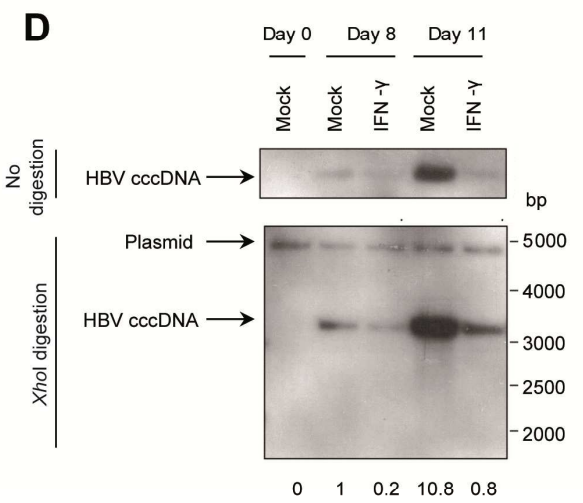


A

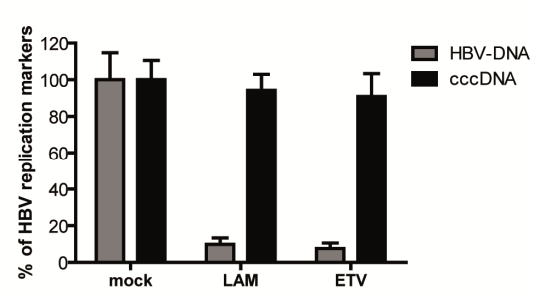

C

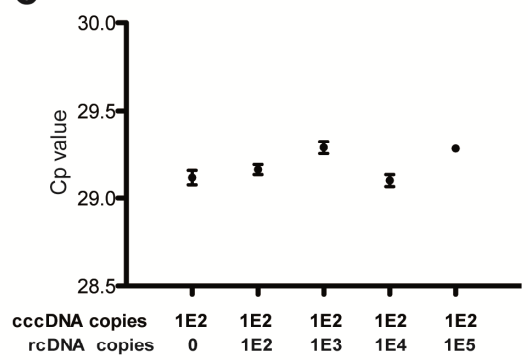

E

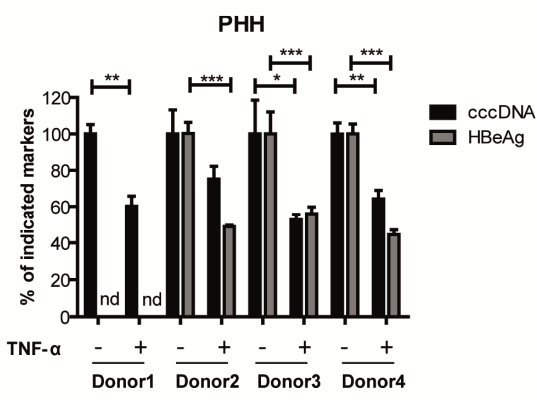

B

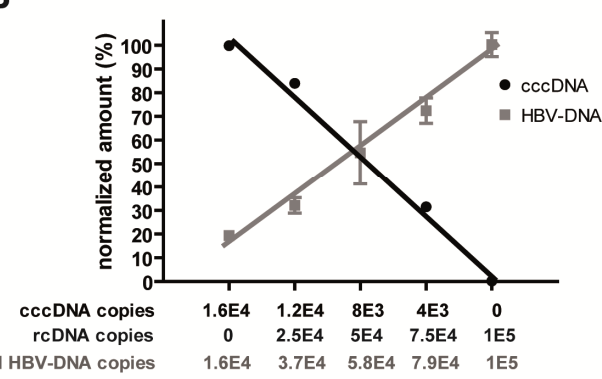

D

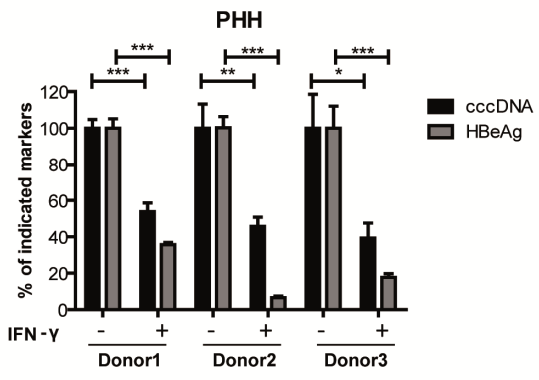

F

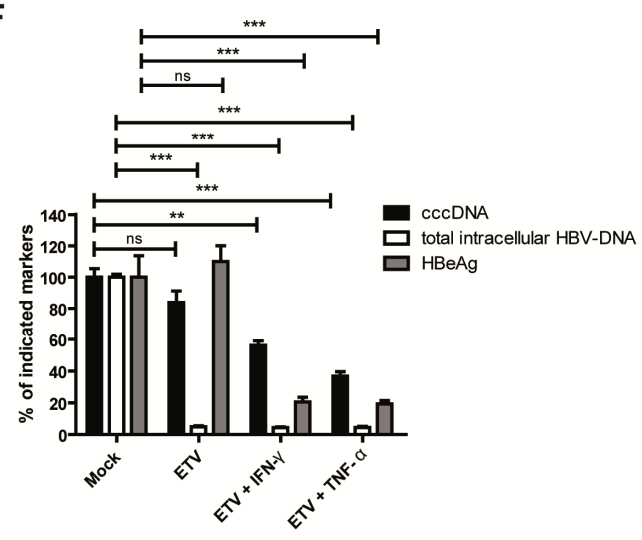


A

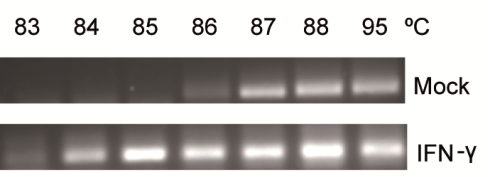

B

$\begin{array}{lllllllll}82 & 83 & 84 & 85 & 86 & 87 & 88 & 95^{\circ} \mathrm{C}\end{array}$

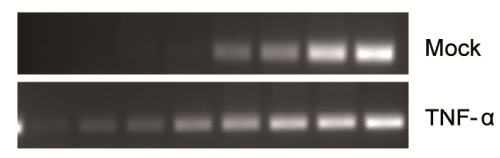

E

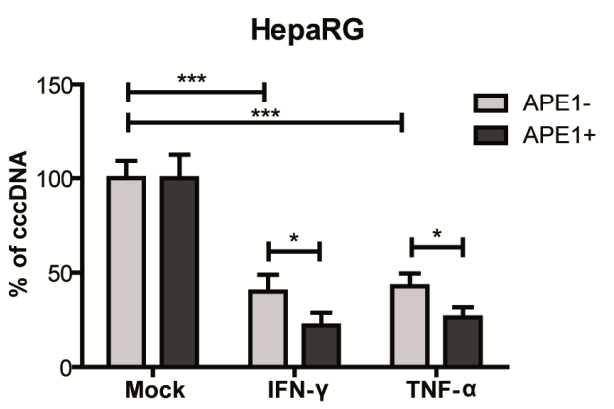

C

D
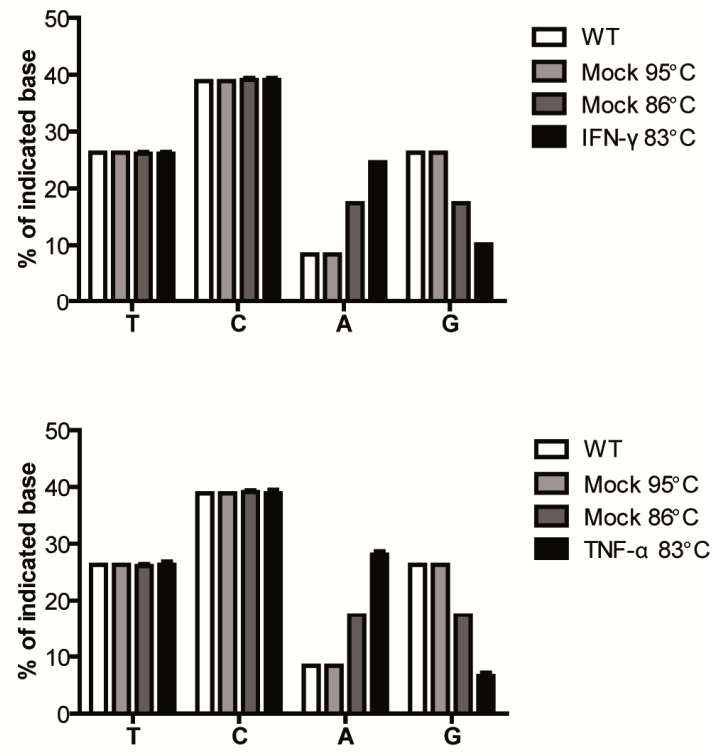

$\mathbf{F}$

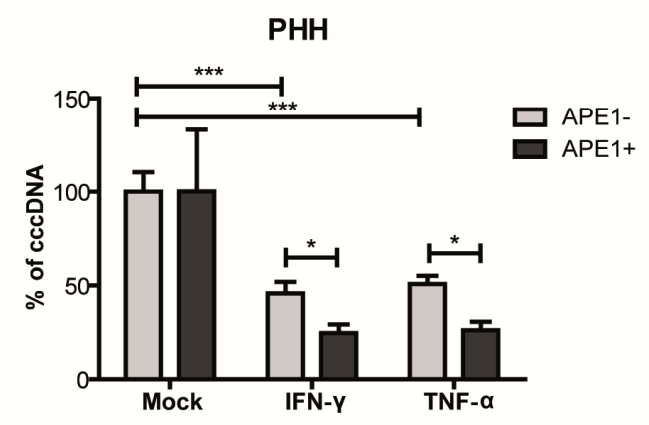


A
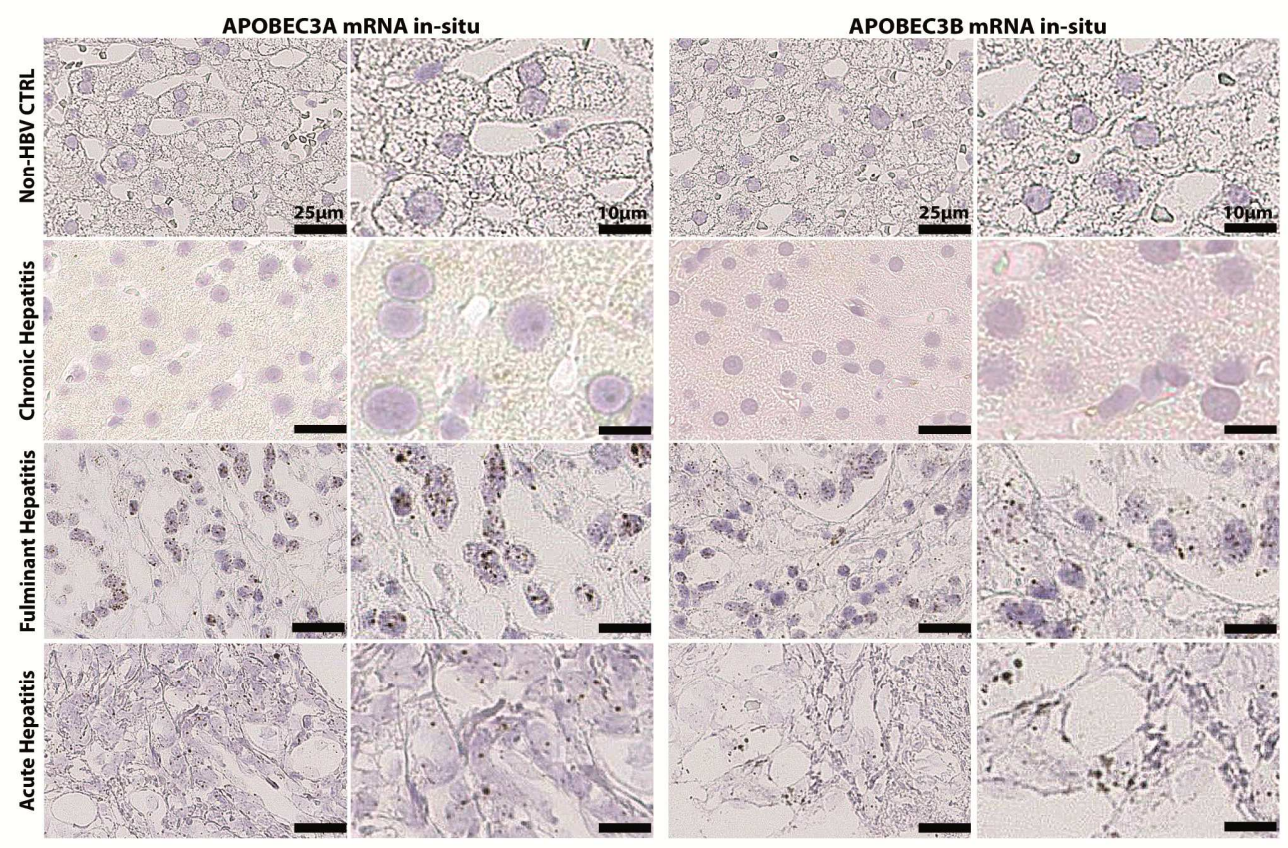

B

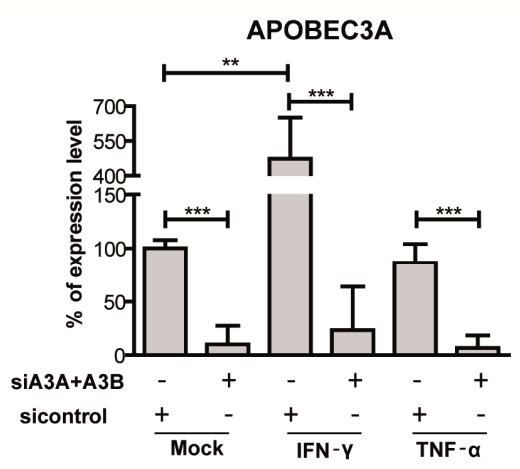

C

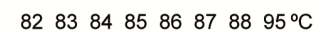

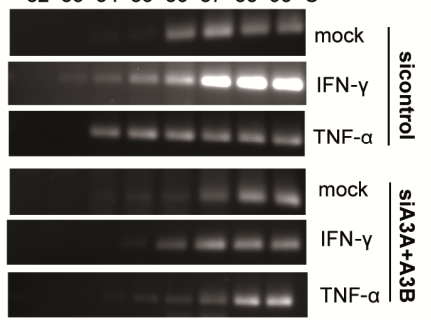

D

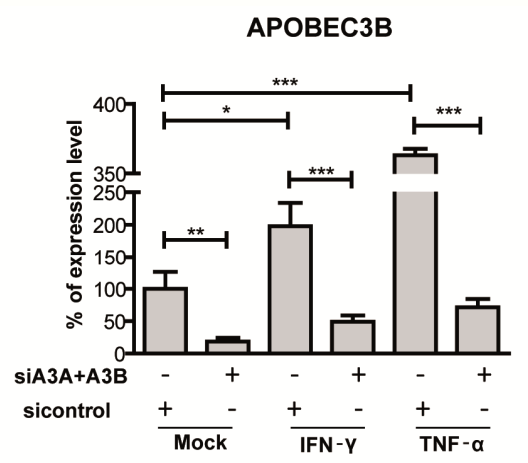

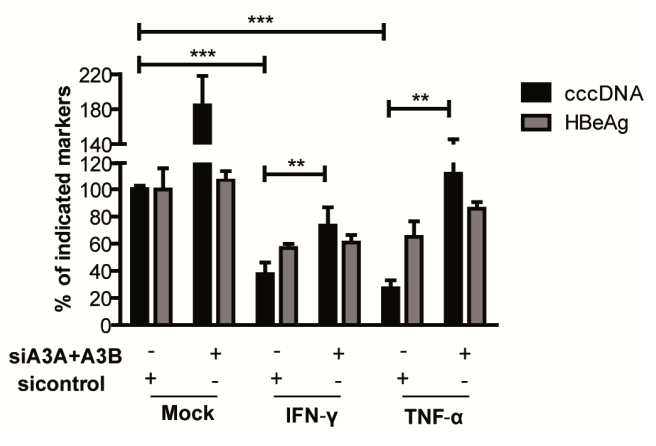


A

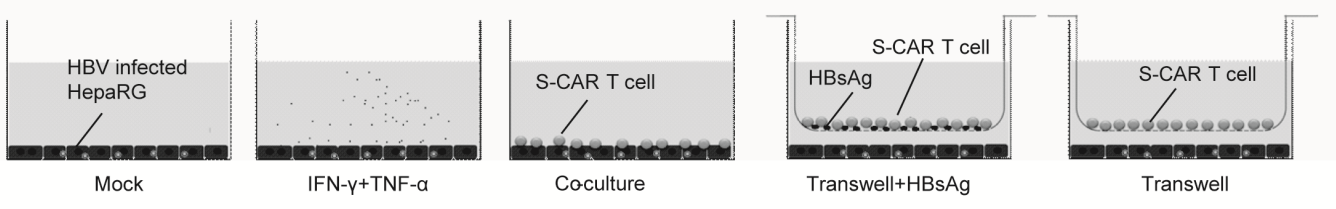

B ALT

C

IFN-Y

TNF- $\alpha$
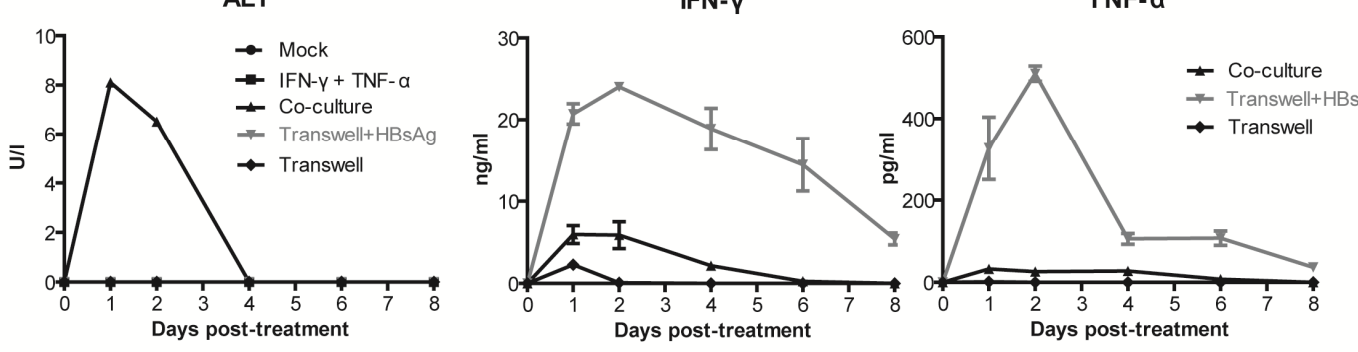

D

E

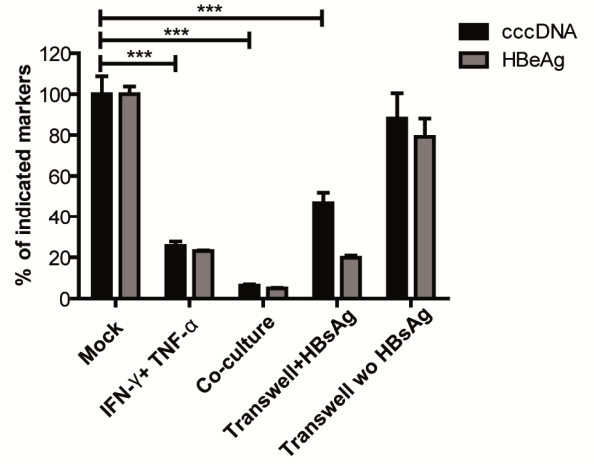

$\begin{array}{lllllllll}82 & 83 & 84 & 85 & 86 & 87 & 88 & 95 & { }^{\circ} \mathrm{C}\end{array}$

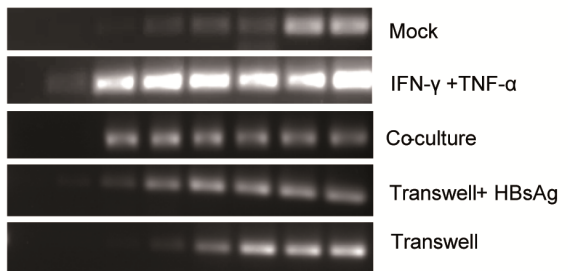


A

T-cell activation

Non-cytolytic T-cell function

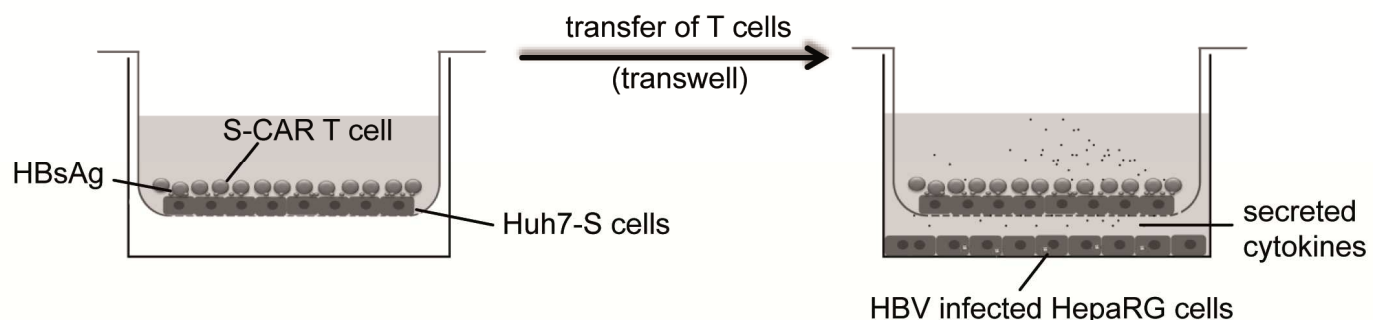

B
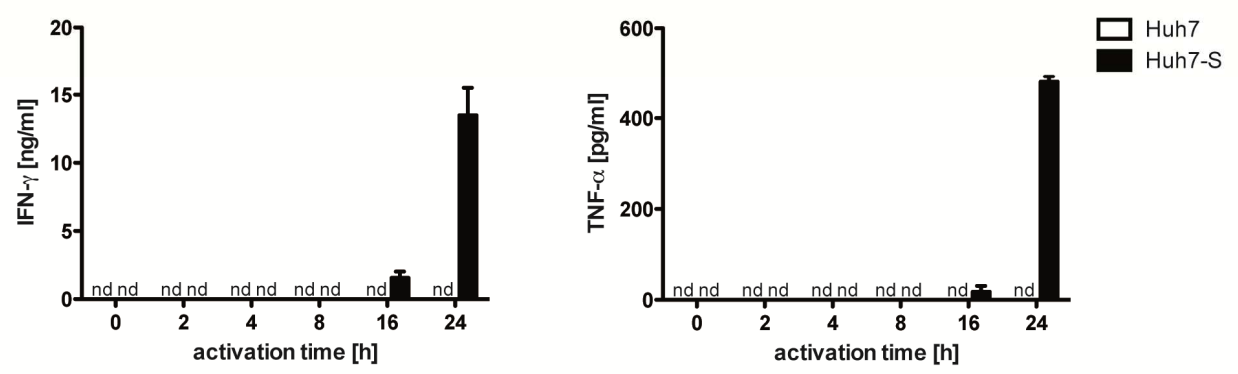

C

D
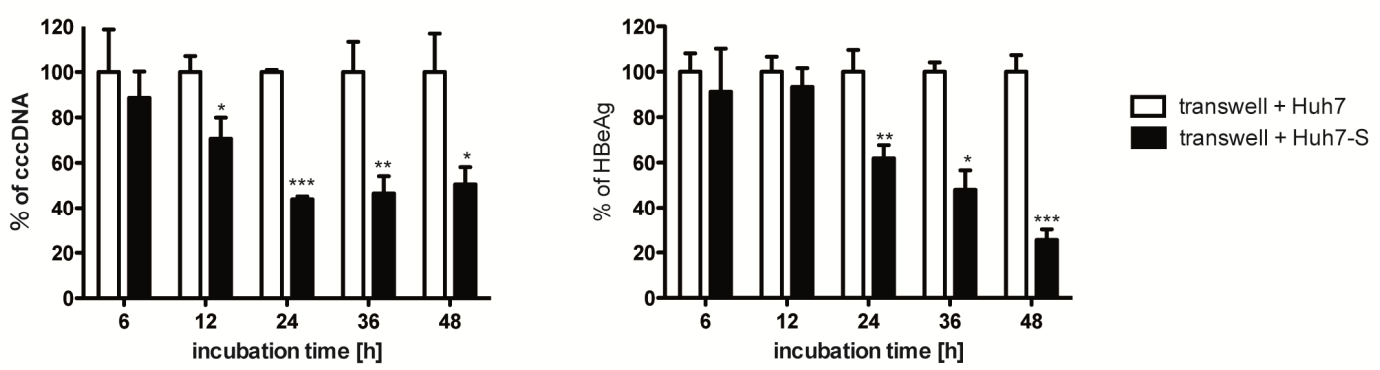

E

$\mathbf{F}$
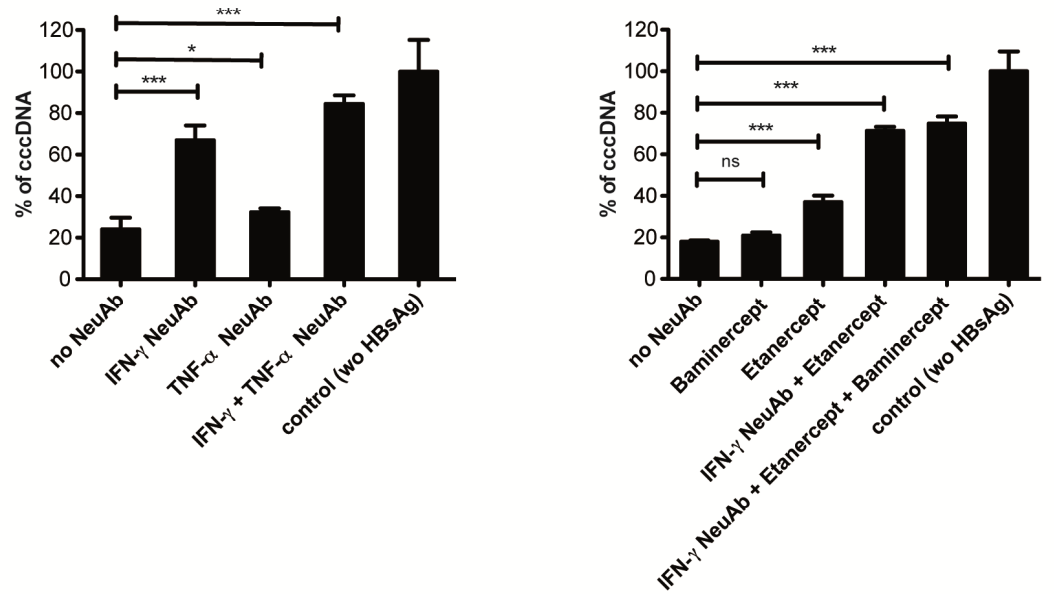


\section{Supplementary Methods}

HBV infection. HBV infection was carried out with concentrated supernatant from HepG2.2.15 cells (at a MOI of $600 \mathrm{vp} /$ cell) or with HBV purified from supernatant of HepAD38 cells by heparin affinity chromatography and subsequent concentration via sucrose gradient ultracentrifugation (at a MOI of $100 \mathrm{vp} / \mathrm{cell}$ ). Infection was performed with 5\%PEG8000 and William's E medium contain 10\% FBS,Penicillin/streptomycin, Human insulin (350ul, sigma 19278), Hydrocortison (5ug/ml, sigma H2270), and $1.8 \%$ DMSO (sigma, 2650).

Generation of HepG2-H1.3 and HepaRG+pEpi-H1.3 cells. Human hepatoma cells HepG2 (ATCC HB-8065) as well as their derivate HepG2-H1.3 were maintained in Dulbecco's Modified Eagles Medium (DMEM) supplemented with 2 mM L-glutamine, $50 \mathrm{U} / \mathrm{ml}$ penicillin, $50 \mu \mathrm{g} / \mathrm{ml}$ streptomycin, $1 \mathrm{mM}$ sodium pyruvate, non-essential amino acids containing, $10 \%$ fetal calf serum (all from Biochrom AG, Berlin, Germany) on collagen type IV coated cell culture dishes at $37^{\circ} \mathrm{C}$ under $5 \% \mathrm{CO} 2$. When the cell layer reached $100 \%$ confluence, serum content was reduced to $1 \%$ and DMSO was added to $1.74 \%$. Cell culture medium was exchanged every second day. HepaRG-pEpi-H1.3 cells were generated by transfecting HepaRG cells with the episomal construct pEpi-H1.3 - derived from cloning of 1.3-fold HBV genome into the episome pEpi-eGFP and selected using $600 \mu \mathrm{g} / \mathrm{ml}$ geneticin. HepaRG+pEpi-H1.3 cells were differentiated for 6 weeks to allow cccDNA accumulation.

Isolation of nucleic acids from HBV capsids. For the analysis of nucleic acids in HBV capsids, $10^{7}$ cells were lysed in $2 \mathrm{ml}$ lysis buffer $(50 \mathrm{mM}$ Tris/HCl pH8.0; $140 \mathrm{mM}$ 
$\mathrm{NaCl} ; 1 \mathrm{mM}$ EDTA, $0.5 \% \mathrm{NP} 40$ ) for 5 minutes on ice. Cell debris and nuclei were sedimented at $400 \times \mathrm{g}$ for $5 \mathrm{~min}$ at $4{ }^{\circ} \mathrm{C}$, and the supernatant containing cytoplasmic HBV capsids was transferred into a fresh tube. $\mathrm{CaCl}_{2}$ was added to a final concentration of $6 \mathrm{mM}$, and free nucleic acids were digested with $100 \mathrm{u}$ micrococcal nuclease (GE Healthcare, Buckinghamshire, UK) at $37^{\circ} \mathrm{C}$ for 30 min before isolation of capsid DNA and RNA.

Detection of HBV antigens and nucleic acids. Secreted hepatitis B e antigen (HBeAg) was determined using commercial immunoassays (Siemens Molecular Diagnostics, Marburg, Germany). For Southern blotting, cellular DNA was extracted as described, ${ }^{13}$ separated through a vertical $0.8 \%$ agarose gel, depurinated in $0.25 \mathrm{M}$ $\mathrm{HCl}$ and blotted onto a positively charged nylon membrane in $0.4 \mathrm{M} \mathrm{NaOH} .500 \mu l$ cell culture supernatant was sucked through a positively charged nylon membrane, denatured in $0.4 \mathrm{M} \mathrm{NaOH}$ and renatured in 2xSSC. HBV DNAs were detected using a ${ }^{32} \mathrm{P}$ labelled HBV DNA probe. For quantitative real time PCR ( $\mathrm{qPCR}$ ), total cellular DNA (NucleoSpin Tissue Kit,) and RNA (NucleoSpin® RNA II kit, Macherey Nagel, Düren, Germany) were extracted using commercial kits. RNA was transcribed into cDNA using SuperScript III reverse transcriptase (Invitrogen, Carlsbad, CA, USA). Total intracellular HBV-DNA, cccDNA or genes of interest were detected using specific PCR primers (Table S1). qPCR were performed using the LightCycler ${ }^{\mathrm{TM}}$ system to ensure rapid cycling and increase specificity of cccDNA detection, and analysed using the second derivative maximum method that includes both 
normalization to a reference gene (PRNP for cccDNA) and to primer efficiency (Roche, Mannheim, Germany). ${ }^{14}$

Generation of S-CAR and TCR grafted T cells. PBMCs were kept in T cell culture medium (TCM: RPMI dutch modified, $10 \%$ human serum, $1 \%$ pen/strep, $1 \%$ glutamine, $1 \%$ sodium pyruvate, $1 \%$ non essential amino acids), and stimulated for two days with $300 \mathrm{U} / \mathrm{ml} \mathrm{IL-2}$ on non-tissue culture plates, which had been coated with $5 \mu \mathrm{g} / \mathrm{ml} \mathrm{OKT-3} \mathrm{and} 0.05 \mu \mathrm{g} / \mathrm{ml}$ anti-CD28 antibody (eBioscience, San Diego, CA, USA) for 2 hours at $37^{\circ} \mathrm{C}$, blocked with $2 \%$ BSA for 30 min and washed with PBS.

For S-CAR and TCR grafting, retrovirus supernatant from stable producer cell line 293vec-RD114-S-CAR or 293 cells transiently transfected with TCR expressing retroviral constructs were used. Retrovirus supernatants were centrifuged at $2000 \times \mathrm{g}$, $32^{\circ} \mathrm{C}$ for 2 hours onto plates coated with $20 \mu \mathrm{g} / \mathrm{ml}$ RetroNectin (Takara, St. Germain en Laye, France). After removal of the supernatant, PBMCs were spinoculated onto the virus-coated plates at $1000 \times \mathrm{g}$ at $32^{\circ} \mathrm{C}$ for $10 \mathrm{~min}$. A second transduction was performed after 24 hours.

in situ hybridization. RNA in situ hybridization was performed using the RNAscope $®$ 2.0 brown FFPE Assay (Advanced Cell Diagnostic) according to the manufacturer protocol. Briefly, $2 \mu \mathrm{m}$ paraffin embedded tissue sections were baken for $1 \mathrm{~h}$ in a dry oven at $60^{\circ} \mathrm{C}$. After de-paraffinization and blocking of endogenous peroxidases, slides were cooked for 15 min before protease digestion. Human APOBEC3A and APOBEC3B specific probes (Advanced Cell Diagnostic, CA,USA ) were incubated for $2 \mathrm{~h}$ at $40^{\circ} \mathrm{C}$ before signal amplification and detection and counterstaining with 
Hematoxylin I according to the assay protocol. Slides were mounted using EcoMount mounting medium (BioCare, Concord, CA) and analyzed using a LEICA SCN400 Slide scanner.

siRNA knock down. siRNAs were obtained from Thermo Fisher Scientific Dharmacon ${ }^{\circ}$ (Lafayette, CO, USA): control siRNA, siRNA against A3A, A3B or APE1 (Accell SMARTpool). Ten days after HBV infection, HepaRG cells were transfected with 40 pmol siRNA using $2 \mu$ l lipofectamin 2000 (Life Technologies, Dreieich, Germany) according to the manufacturer's instructions.

LDH release assay. To measure cell death, CytoTox-ONE ${ }^{T M}$ Homogeneous Membrane Integrity Assay (G7890, Promega) was used to quantify LDH release into the medium according to the manufacturer's instructions.

Human cytokine array. Cytokine Human Membrane Antibody Array (ab133997, Abcam) was used to investigate cytokine secretion profiles in cell culture supernatants. $1 \mathrm{ml}$ of undiluted supernatant was used for each membrane and protocol of the manufacturer was followed with sample incubation overnight at $4^{\circ} \mathrm{C}$, large volume wash and incubation with Biotin-Conjugated Anti-Cytokine Mix overnight at $4^{\circ} \mathrm{C}$. Densitometry data was obtained using ImageJ (Rasband, W.S., ImageJ, U. S. National Institutes of Health, Bethesda, Maryland, USA, http://imagej.nih.gov/ij/, 1997-2014) and used to compare different samples after background subtraction and normalization to positive control spots. To determine antibody patterns in human sera, the Luminex-based multiplex protein array technique was utilized, i.e. human 27-plex 
and human 23-plex assays (BioRad Laboratories, Hercules, USA) according to the manufacturer's protocols.

Generation of Huh7-S cells. Human hepatoma cell line Huh7 was cotransfected with an HBs-expressing plasmid and a plasmid carrying a blasticidin resistance gene. After selection with $10 \mu \mathrm{g} / \mathrm{ml}$ blasticidin, a clonal cell line was selected by limiting dilution. Both Huh7 and Huh7-S cells were maintained in Dulbecco's Modified Eagles Medium (DMEM) supplemented with $2 \mathrm{mM}$ L-glutamine, $50 \mathrm{U} / \mathrm{ml}$ penicillin, $50 \mu \mathrm{g} / \mathrm{ml}$ streptomycin, $1 \mathrm{mM}$ sodium pyruvate, non-essential amino acids and $10 \%$ fetal calf serum at $37^{\circ} \mathrm{C}$ under $5 \% \mathrm{CO} 2$, with addition of $10 \mu \mathrm{g} / \mathrm{ml}$ blasticidin for Huh7-S cells.

Immunofluorescence staining. Cells were fixed in 4\% paraformaldehyde for $30 \mathrm{~min}$ and stained using antibodies against cleaved caspase 3 (9661, Cell signaling) and phalloidin (A12381, Life Technologies). $0.5 \mu \mathrm{g} / \mathrm{ml}$ staurosporine was added 12 hours before fixation to induce caspase 3 cleavage. 


\section{Supplementary Tables}

Table S1: Primers used for qPCR.

\begin{tabular}{|l|l|}
\hline Name & Sequence 5'-3' $^{\prime}$ \\
\hline cccDNA 92 fw & GCCTATTGATTGGAAAGTATGT \\
\hline cccDNA 2251 rev & AGCTGAGGCGGTATCTA \\
\hline PRNP fw & GACCAATTTATGCCTACAGC \\
\hline PRNP rev & TTTATGCCTACAGCCTCCTA \\
\hline GAPDH fw & ACCAACTGCTTAGCCC \\
\hline GAPDH rev & CCACGACGGACACATT \\
\hline HBxin fw & ATGGCTGCTARGCTGTGCTGCCAA \\
\hline HBxin rev & AAGTGCACACGGTYYGGCAGAT \\
\hline APOBEC3A fw & AAGGGACAAGCACATGGAAG \\
\hline APOBEC3A rev & TGTGTGGATCCATCAAGTGTC \\
\hline APOBEC3B fw & CGCCAGACCTACTTGTGCTA \\
\hline APOBEC3B rev & GCCACAGAGAAGATTCTTAGCC \\
\hline rCDNA1745 fw & GGAGGGATACATAGAGGTTCCTTGA \\
\hline rcDNA1844 rev & GTTGCCCGTTTGTCCTCTAATTC \\
\hline mitoDNA 8686 fw & CCCTCTCGGCCCTCCTAATAACCT \\
\hline mitoDNA 8796 rev & GCCTTCTCGTATAACATCGCGTCA \\
\hline Kan-L & GGCAGGATCTCCTGTCATCT \\
\hline Kan-R & CATCAGCCATGATGGATACTTTC \\
\hline APE1-L & GCTTCGAGCCTGGATTAAGA \\
\hline APE1-R & TTGGTCTCTTGAAGGCACAGT \\
\hline
\end{tabular}




\section{ACCEPTED MANUSCRIPT}

Table S2. Demographic background, biochemical characteristics and viremia in acute and chronic hepatitis $B$ patients.

Distributions of continuous variables were described as median values and ranges. $P$ values were determined by Mann-Whitney $U$ test. (ALT: alanine aminotransferase; AST: aspartate aminotransferase)

\begin{tabular}{|l|l|l|l|}
\hline & acute HepB & chronic HepB & P value \\
\hline Age & $37(26-76)$ & $38(16-70)$ & 0.4613 \\
\hline Gender (M/F) & $4 / 5$ & $4 / 7$ & \\
\hline ALT (U/I) & $3176(93-3530)$ & $45(17-623)$ & 0.0045 \\
\hline AST (U/I) & $1493(43-1825)$ & $32(18-329)$ & 0.0116 \\
\hline Billirubin (mg/dl) & $15.1(4.9-37.6)$ & $0.3(0.2-5.3)$ & 0.0033 \\
\hline HBV-DNA (IU/ml) & $4.6 \times 10^{6}\left(1 \times 10^{5}-5.6 \times 10^{7}\right)$ & $1.2 \times 10^{6}\left(<25-1.1 \times 10^{8}\right)$ & 0.4713 \\
\hline
\end{tabular}


A

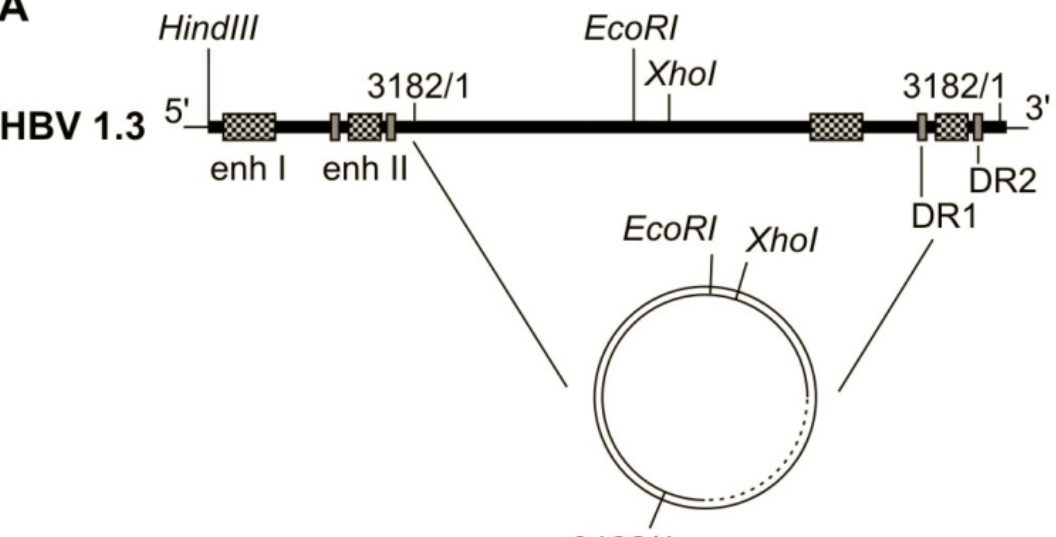

$3182 / 1$

$3.5 \mathrm{~kb}$

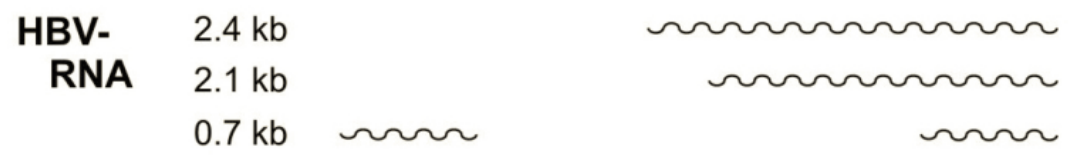

HBV-

proteins

\section{\begin{tabular}{ll|l|l|} 
core $\quad \mathrm{L}$ & $\mathrm{M}$ & $\mathrm{S}$ \\
\hline
\end{tabular}}

polymerase

B

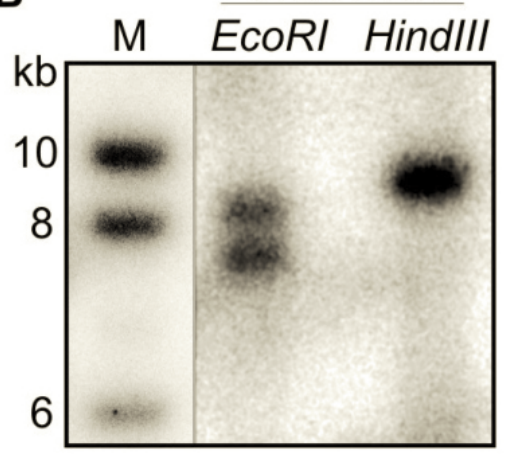

C - Xhol

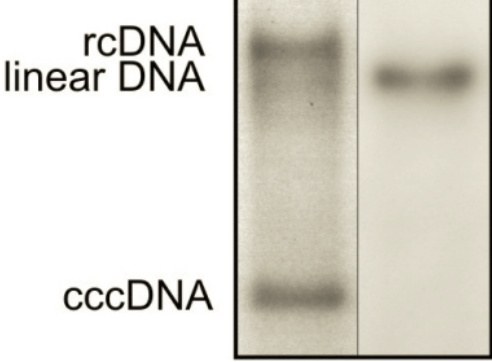

Figure S1:Generation and characterization of HepG2-H1.3 cells.

(A) Schematic representation of construct $\mathrm{H} 1.3$ comprising a 1.3-fold overlength genome of HBV genotype D, subtype ayw, which was stably integrated into hepatoma HepG2 cells. As depicted, the viral genome carries a linearized HBV genome and a 5 'terminal redundancy, which comprises HBV enhancer elements (enh) I and II, direct repeats DR1 and DR2 as well as X, precore/core and pregenomic promotors and transcription initiation sites. Therefore, all HBV RNAs are transcribed from construct $\mathrm{H} 1.3$ under control of the endogenous HBV promotor / enhancer elements: pregenomic ( $3.5 \mathrm{~kb})$ RNA containing encapsidation signal as well as subgenomic RNA's $(2.4 \mathrm{~kb}, 2.1 \mathrm{~kb}$ and $0.7 \mathrm{~kb}$ ). Unique restriction sites for EcoRI, Hindlll and Xhol are indicated. (B) Southern blot analysis of genomic DNA isolated from HepG2-H1.3 cells following restriction digestion with EcoRI (left lane) or Hindlll (right lane) using a 32P-labelled HBV-DNA probe. $M=$ DNA size marker. (C) Southern blot analysis of low molecular weight DNA containing HBV cccDNA as well as relaxed circular forms (rcDNA) extracted from HepG2-H1.3 cells following a modified Hirt lysis; DNA was not digested (-) or linearized with Xhol. 


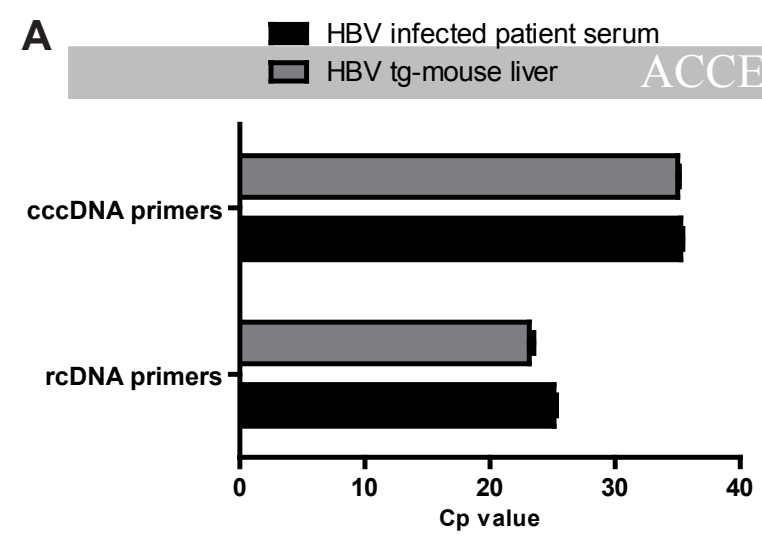

B

HepaRG

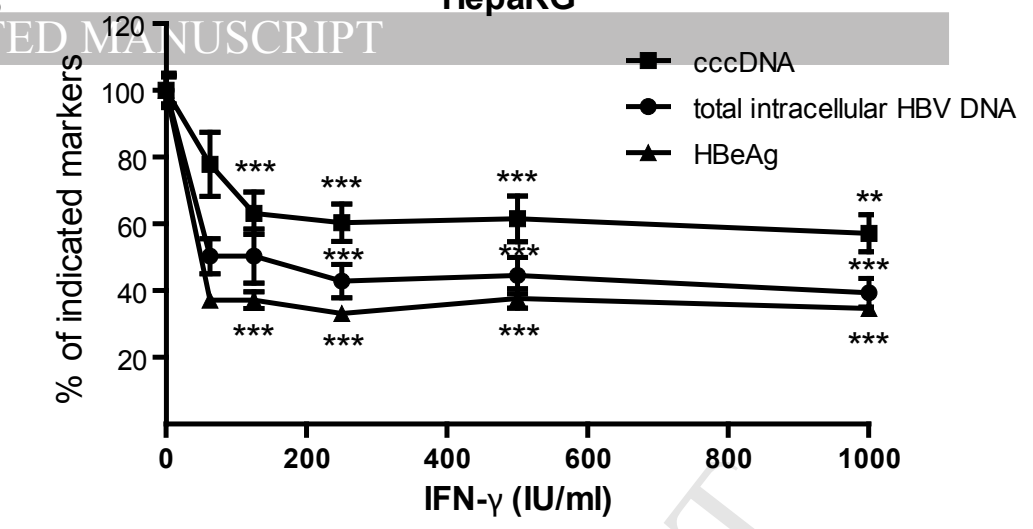

C
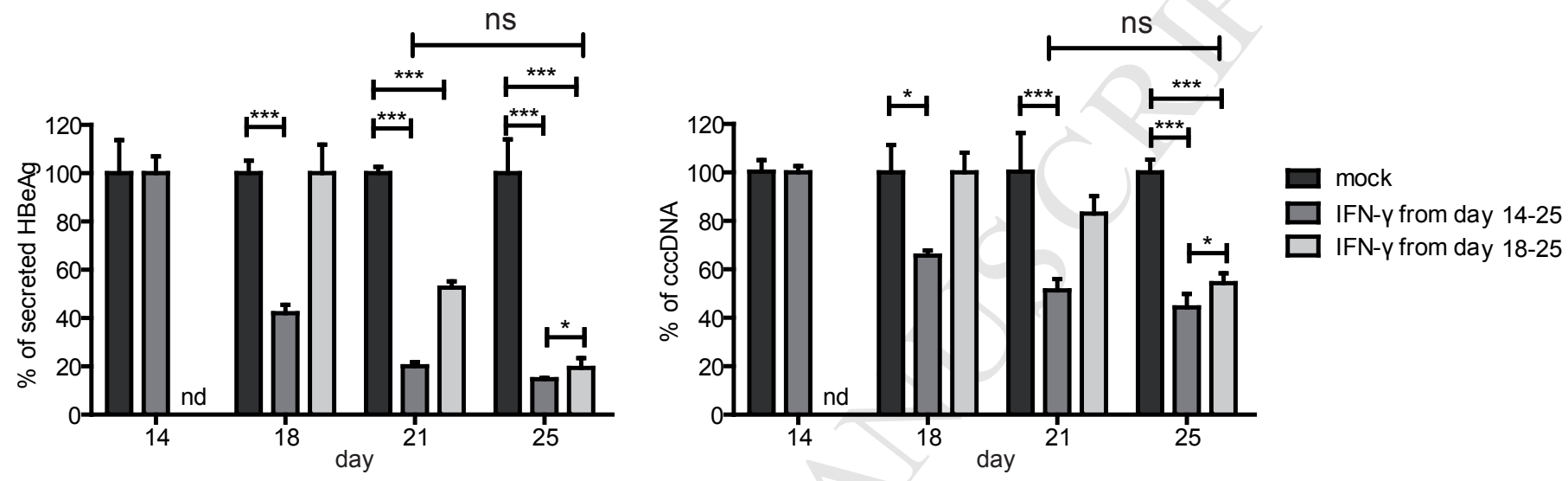

D

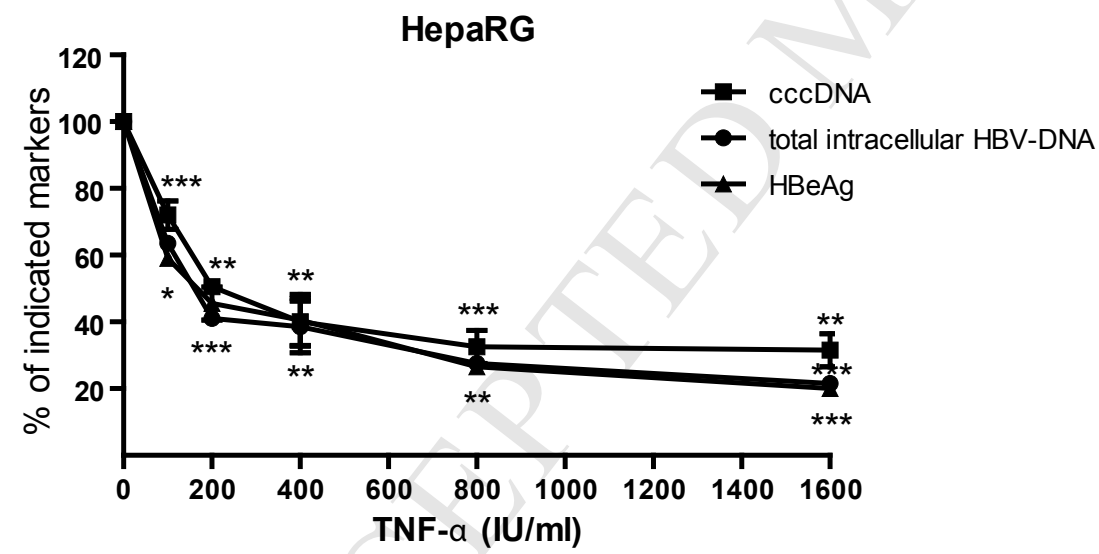

Figure S2: Antiviral effects of IFN- $y$ and TNF- $\alpha$ on HBV infected dHepaRG cells.

(A)Total DNA isolated from HBV infected patient serum or HBVtg-mouse liver was evaluated by qPCR, Cp values using cccDNA-specific or total HBV-DNA primers were determined. HBV infected HepaRG cells were treated with indicated doses of (B) IFN-y or (D) TNF- $\alpha$ for 7 days.

(C) Differentiated HepaRG cells were infected by HBV. Cells were treated with IFN- $(500 \mathrm{IU} / \mathrm{ml}$ ) twice per week from day 14 or day 18 until day 25 post-infection. The contents of cccDNA or intracellular HBV-DNA relative to PRNP were analyzed by qPCR and HBeAg in the supernatant were quantified by ELISA (nd, not determined). Data are given as mean \pm SD. 
A

BACCEPTED MANUSCRIPT C

IFN- $Y$

TNF- $\alpha$
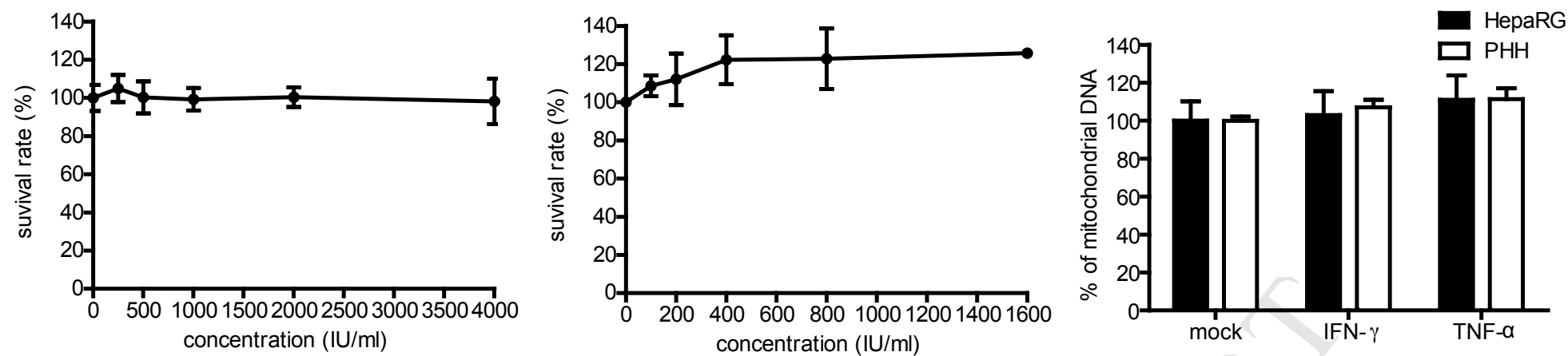

D

mock

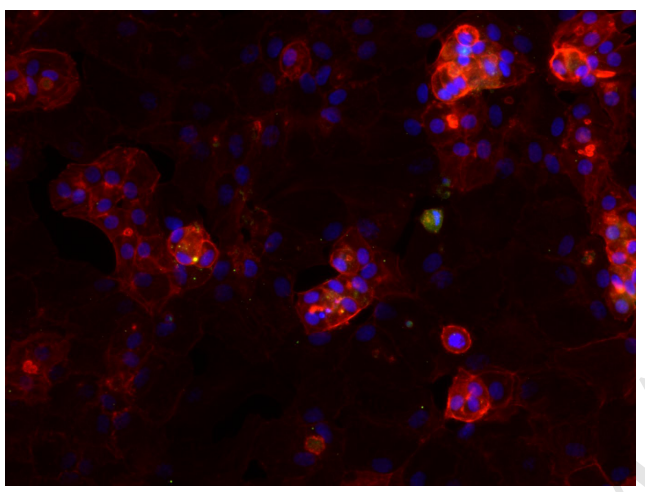

IFN- $\gamma$

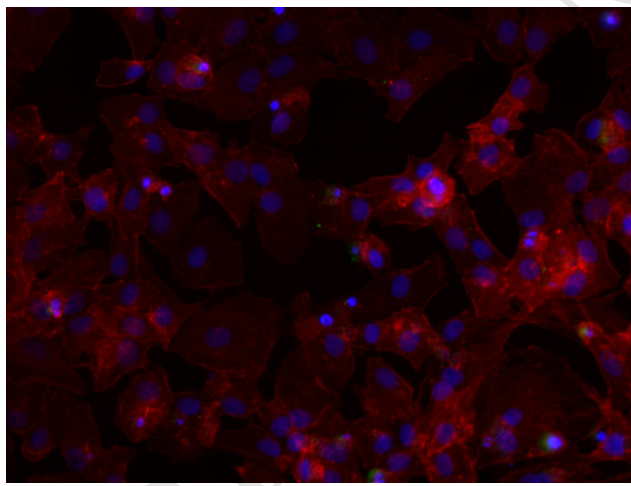

Staurosporin

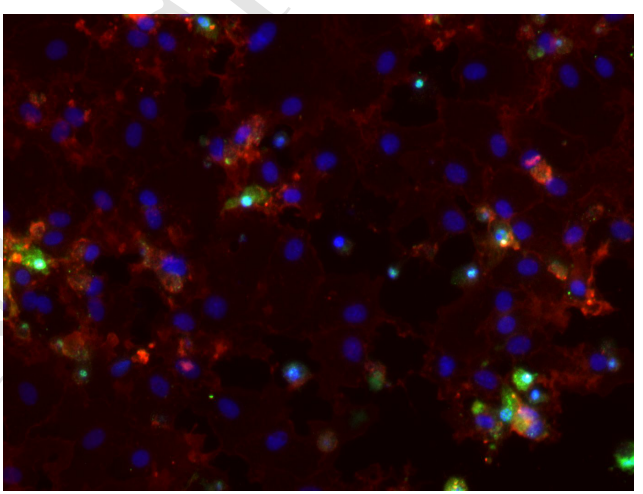

TNF- $\alpha$

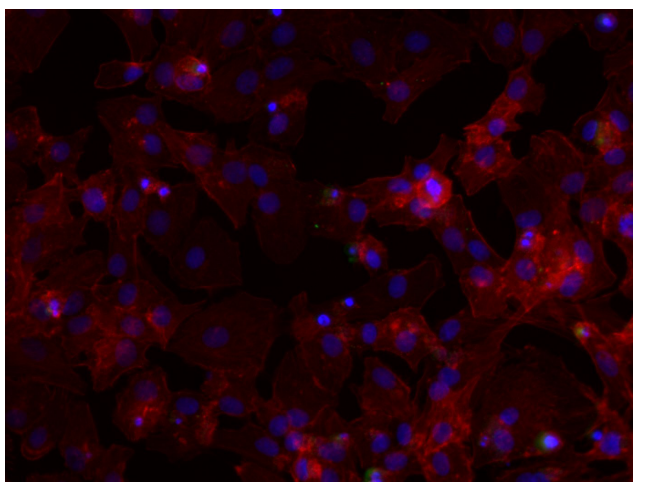

E

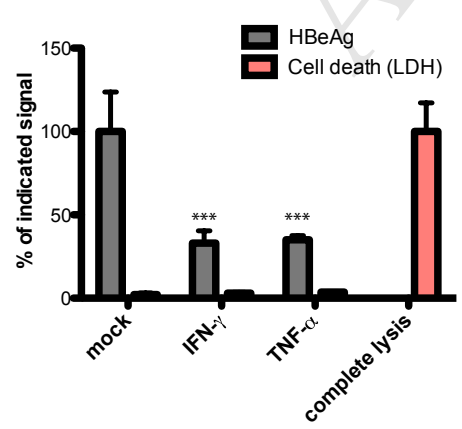

$\mathbf{F}$
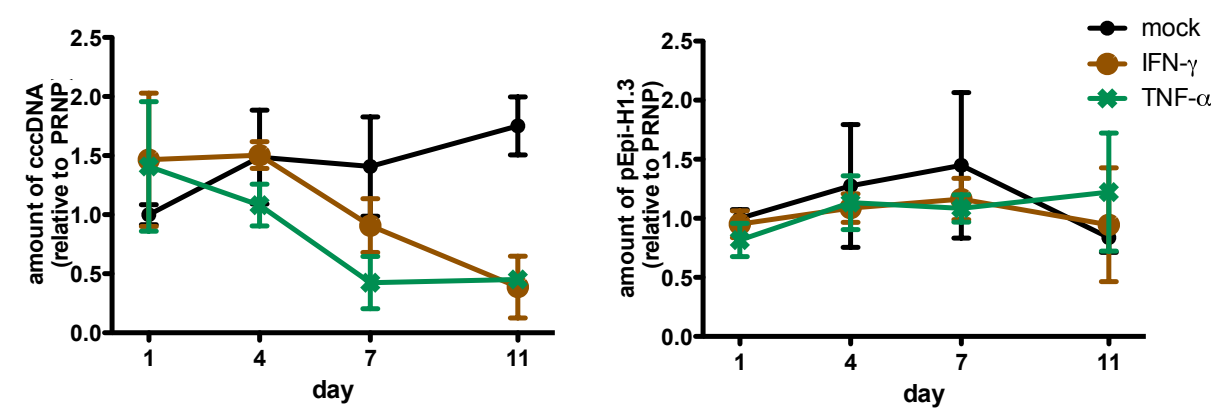

Figure S3: Cytotoxicity test and cccDNA specific degradation.

HBV infected dHepaRG cells were treated with indicated doses of (A) IFN- $\gamma$ or (B) TNF- $\alpha$ for 7 days. Cell viability was determined by XTT assay and is shown in \% of untreated controls. (C-E) HBV infected dHepaRG and PHH were treated with $200 \mathrm{IU} / \mathrm{ml}$ IFN-y or 800 IU/ml TNF- $\alpha$ for 7 days and analyzed for signs of cell death. (C) Total cellular mitochondrial DNA was quantified by qPCR.(D) Cells were visualized with phalloidin (red) and stained for cleaved caspase 3 (green). Staurosporin was used as positive control to induce cell death. (E) Cell culture supernatants were analyzed for LDH release. (F) Differentiated HepaRG-pEpi-H1.3 cells expressing HBV from an episomal pEpi-H1.3 construct were treated with IFN-y (200 IU/ml) or TNF- $\alpha$ (800 IU/ml) for 11 days. HBV cccDNA and pEpi-H1.3 DNA were quantified by specific qPCR. 
A

WT

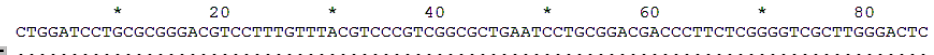

mock $95^{\circ} \mathrm{C}$

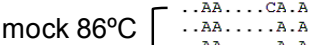

IFN-y $83^{\circ} \mathrm{C}[$

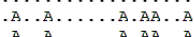

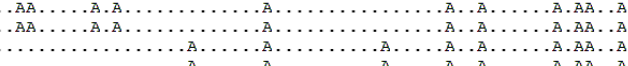

W.W.A.A.A.

A.A.A. A.

AA .A. . . . . A.A......... :

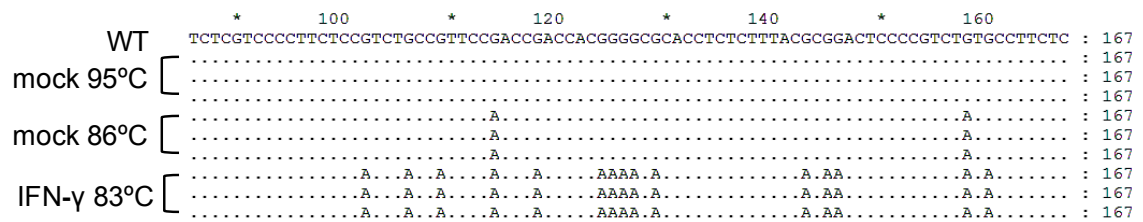

B

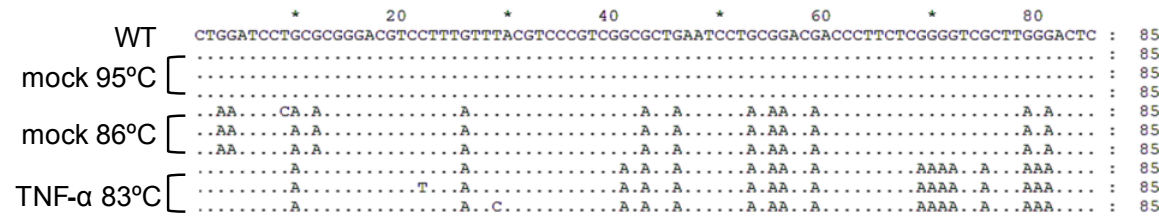

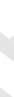

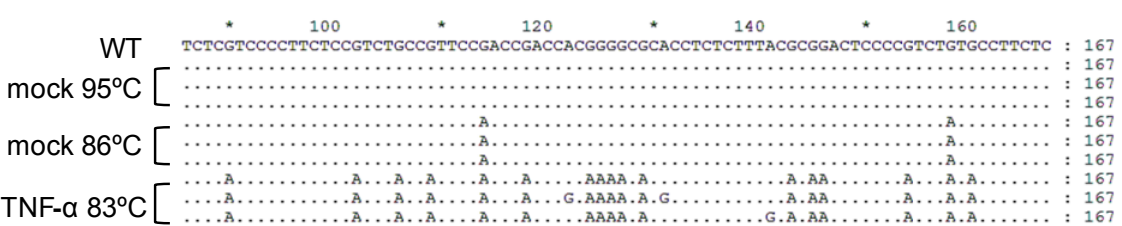

C

\section{cccDNA}

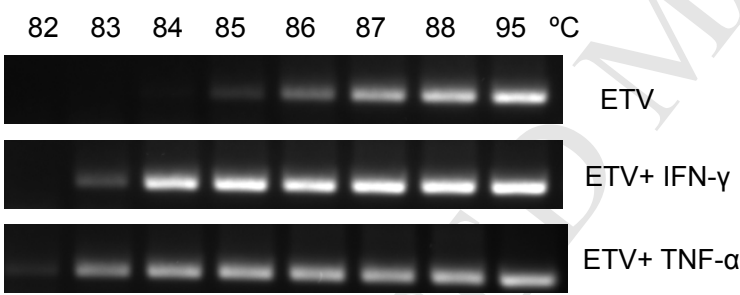

D

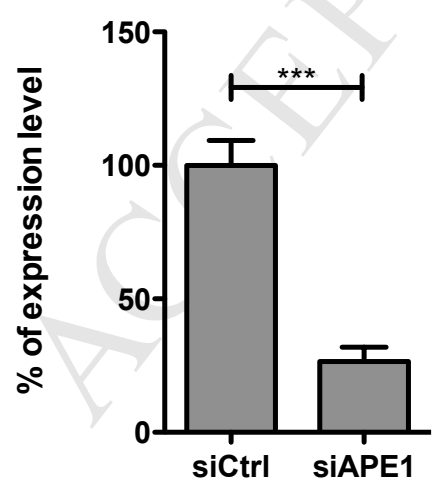

E

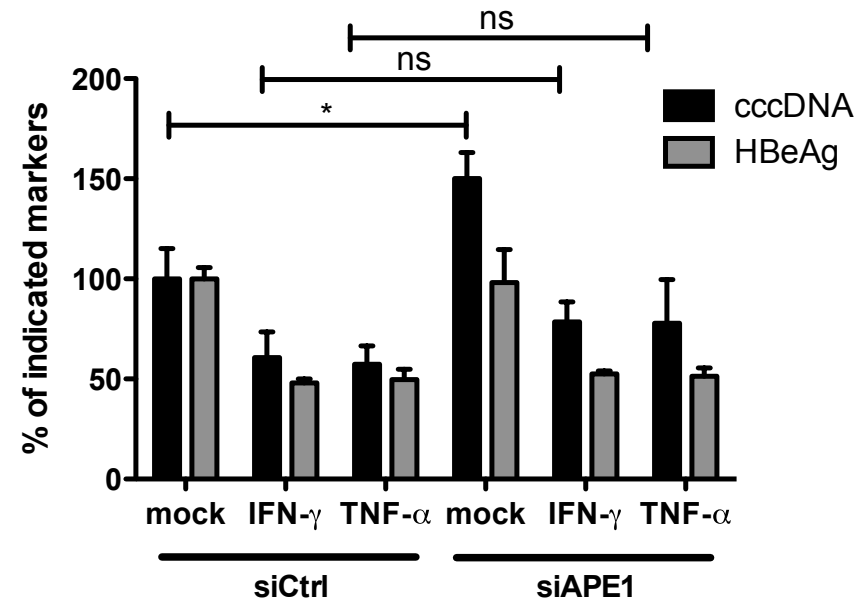

Figure S4: Analysis of cccDNA modifications.

HBV infected dHepaRG cells were treated with (A) $200 \mathrm{IU} / \mathrm{ml}$ IFN-y or (B) $800 \mathrm{lU} / \mathrm{ml}$ TNF- $\alpha$ for 10 days. 3D- PCR analysis was performed on cccDNA. 3D-PCR products obtained at 83,86 or $95^{\circ} \mathrm{C}$, respectively, were cloned and sequenced. (C) HBV infected dHepaRG cells were treated with $0.5 \mu \mathrm{M}$ ETV for 7 days or pretreated with ETV for 2 days followed by ETV plus $200 \mathrm{IU} / \mathrm{ml}$ IFN- $\gamma$ or $800 \mathrm{IU} / \mathrm{ml}$ TNF- $\alpha$ for 5 days. 3D-PCR analyses were performed on cccDNA. (D,E) HBV infected dHepaRG cells were treated with $200 \mathrm{IU} / \mathrm{ml} \mathrm{IFN}-\mathrm{y}$ or $800 \mathrm{IU} / \mathrm{ml}$ TNF- $\alpha$ and transfected with siRNA against APE1. (D) Expression of APE1 was analyzed by qRT-PCR. (E) CcCDNA and HBeAg were determined by qPCR and ELISA respectively. 
A

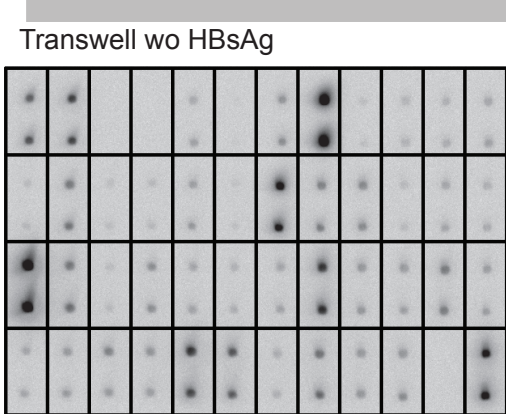

ACCEPTED MANUSCRIB

Transwell + HBsAg
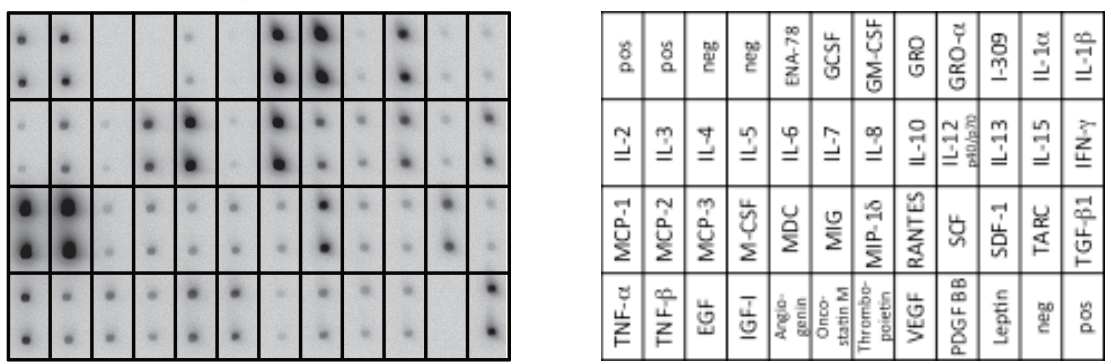

Co-culture

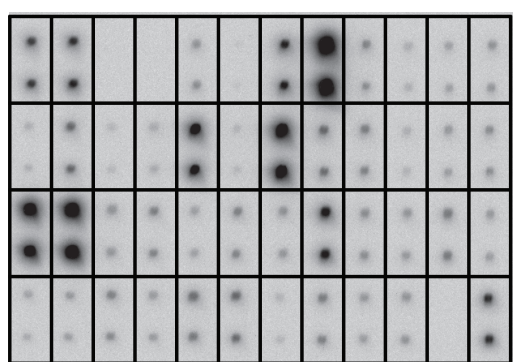

S-CAR TCs +HBsAg

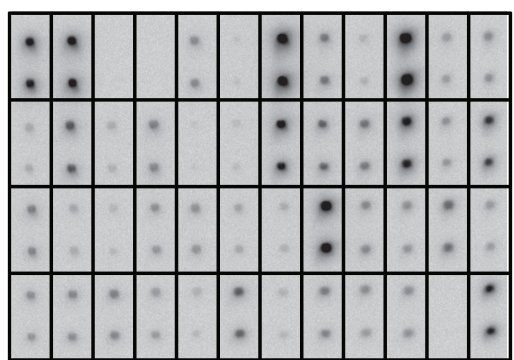

C

D

Cytokine production by HBs stimulated S-CAR TCs and hepatocytes

(Transwell+HBsAg relative to Transwell wo HBsAg)

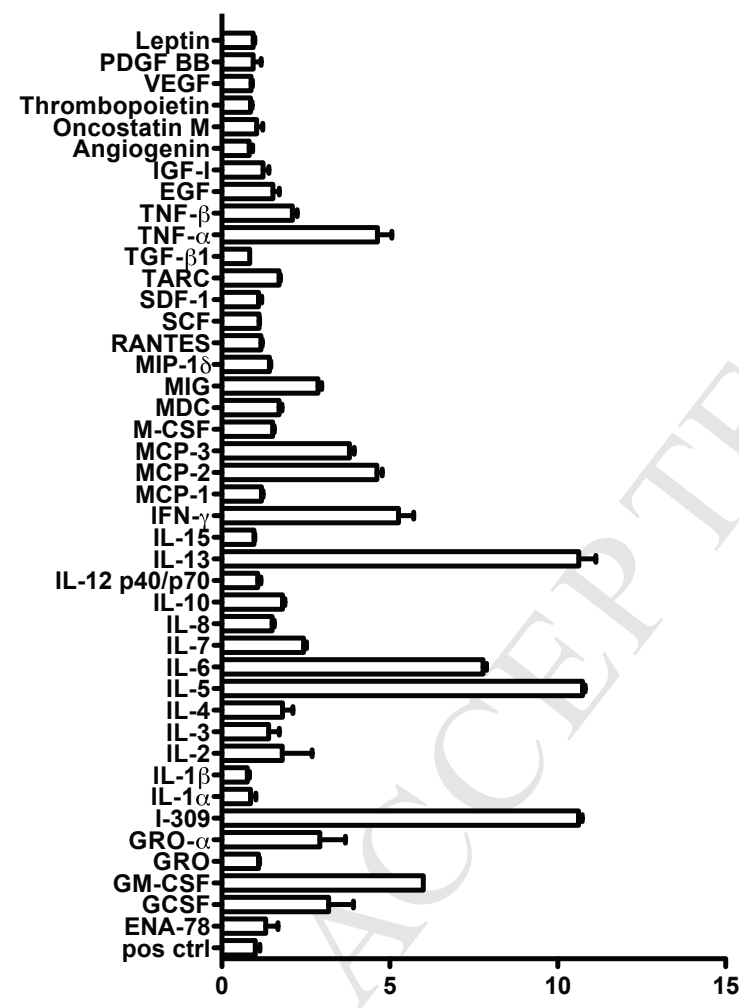

Fold change of cytokine amounts

Cytokine production by hepatocytes

(Transwell+HBsAg relative to S-CAR TCs+HBsAg)

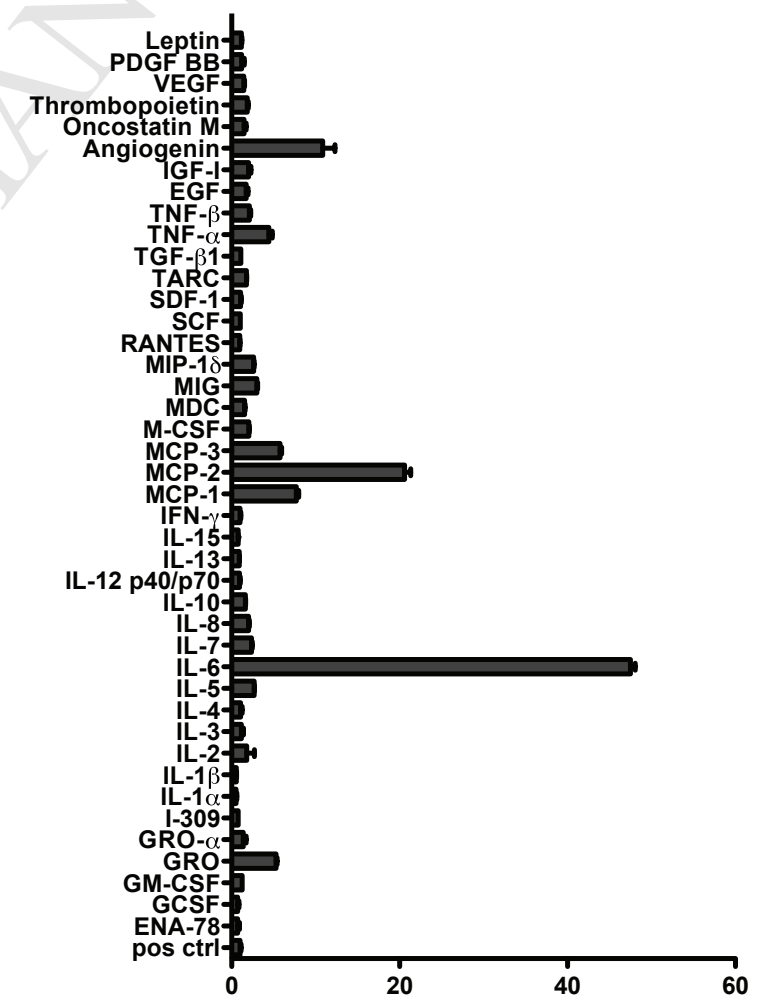

Fold change of cytokine amounts

Figure S5:Human cytokine array.

Human cytokine antibody array membranes were used to determine the cytokine profiles from cell culture supernatants of S-CAR grafted T cells co-cultured with HBV-infected dHepaRG cells in a transwell experiment (see Fig. 6). (A) Unstimulated S-CAR T cells and infected dHepaRG cells (upper left), HBsAg stimulated S-CAR T cells and HepaRG (upper right), S-CAR T cells co-cultured with infected HepaRG (lower left) and HBsAg stimulated S-CAR T cells in absence of hepatocytes (lower right) were analyzed for the secretion of 42 different cytokines indicated in (B). (C) Densitometry data were quantified by Image J. After background subtraction and normalization to positive control spots, sample "Transwell + HBsAg" was compared to sample "Transwell wo HBsAg" to determine the overall cytokine production by T and HepaRG cells. (D) Comparison of sample "Transwell + HBsAg" to sample "S-CAR T cells + HBsAg" to indicate the cytokine production by HepaRG cells. 
A

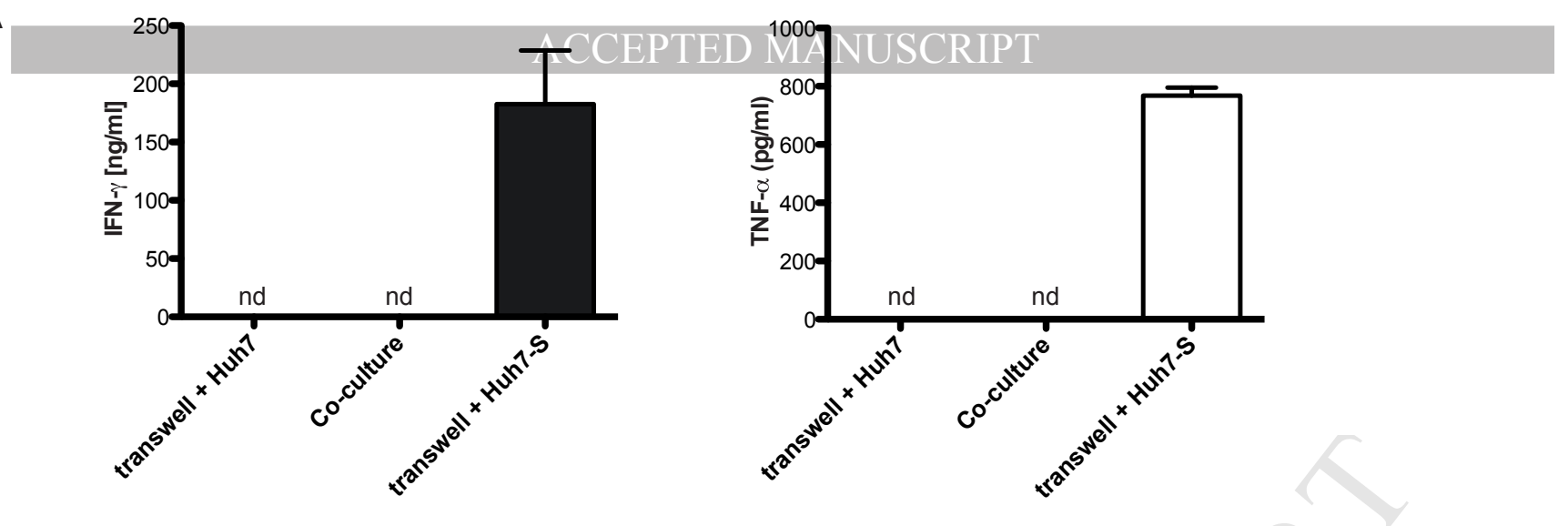

B

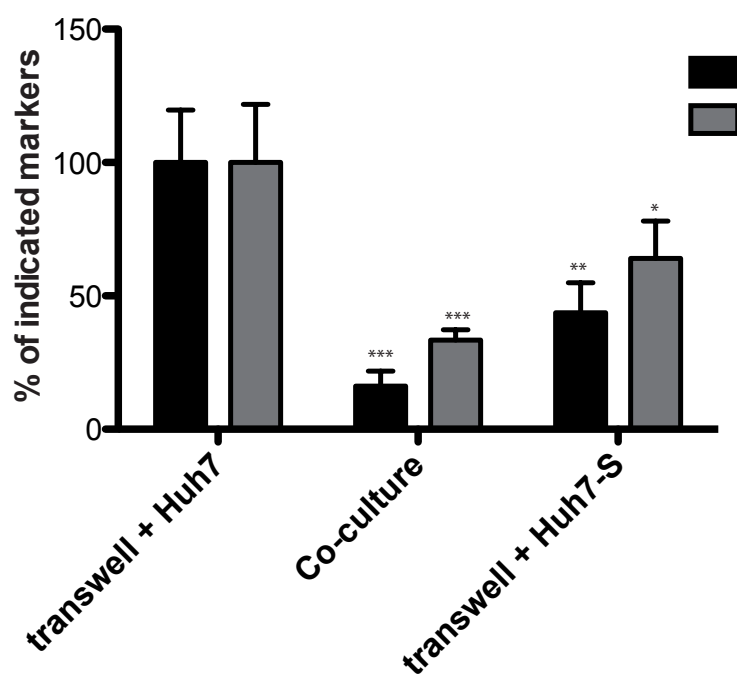

cccDNA

$\mathrm{HBeAg}$

C
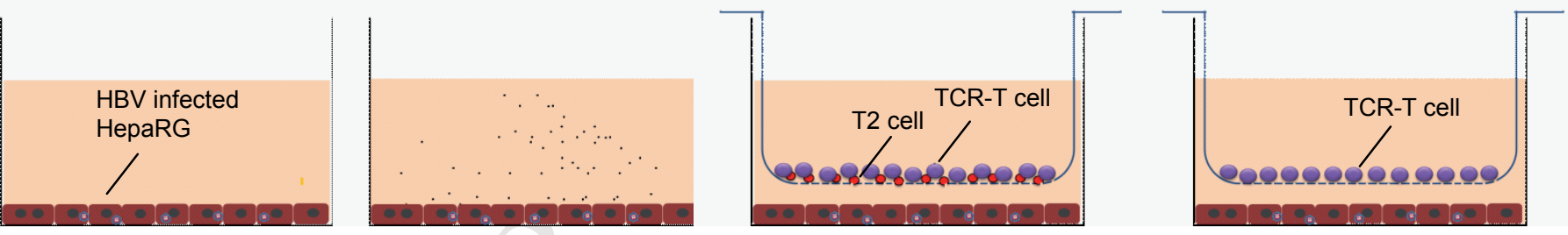

E
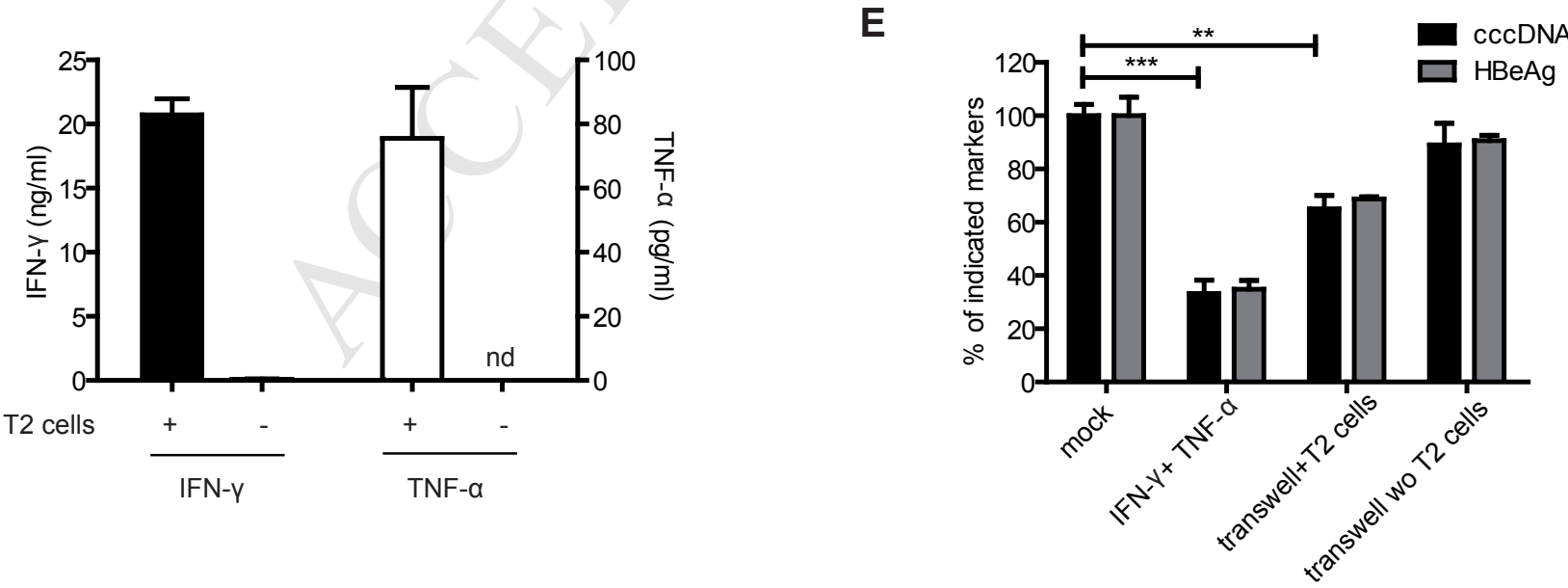

Figure S6: Non-cytolytic antiviral effect of T cells.

HBV infected dHepaRG cells were co-cultured with S-CAR grafted T cells or cultured in the bottom well of a Transwell culture system and S-CAR T cells were separated in the upper chamber and stimulated with Huh7 (negative control) or Huh7-S cells and removed after 2 days (day 2). (A) IFN-y and TNF-a secreted into the cell culture supernatant on day 2. (B) HBV cccDNA relative to PRNP and HBeAg at day 8 quantified by qPCR and ELISA, respectively. (C) HBV infected dHepaRG cells were cultured in lower wells of a Transwell culture system either without any treatment, or treated with IFN-y and TNF- $\alpha$, or directly cocultured with TCR C18-transduced T cells, or co-cultured with TCRC18-transduced T cells separated in the upper chamber and stimulated by T2 cells preincubated with HBV peptide C18 or without. (D) IFN-y and TNF- $\alpha$ secrected into the cell culture supernatant on day 7. (E) HBV cccDNA relative to PRNP were analyzed by qPCR, and $\mathrm{HBeAg}$ in the supernatant was quantified by ELISA. (nd, below detection limit). 

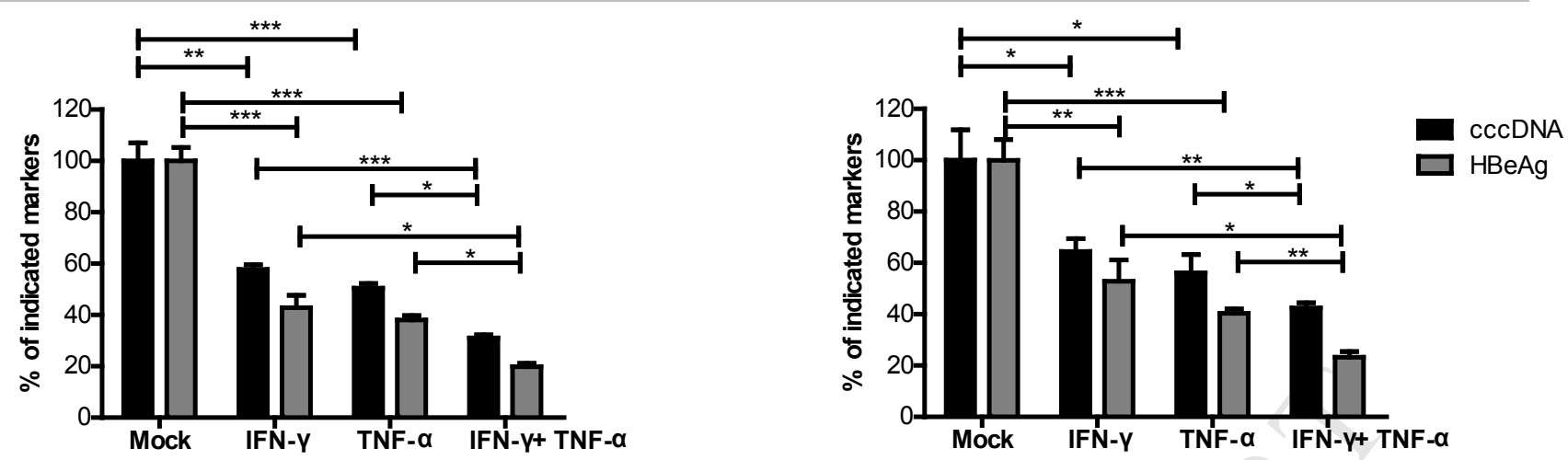

C

HepaRG
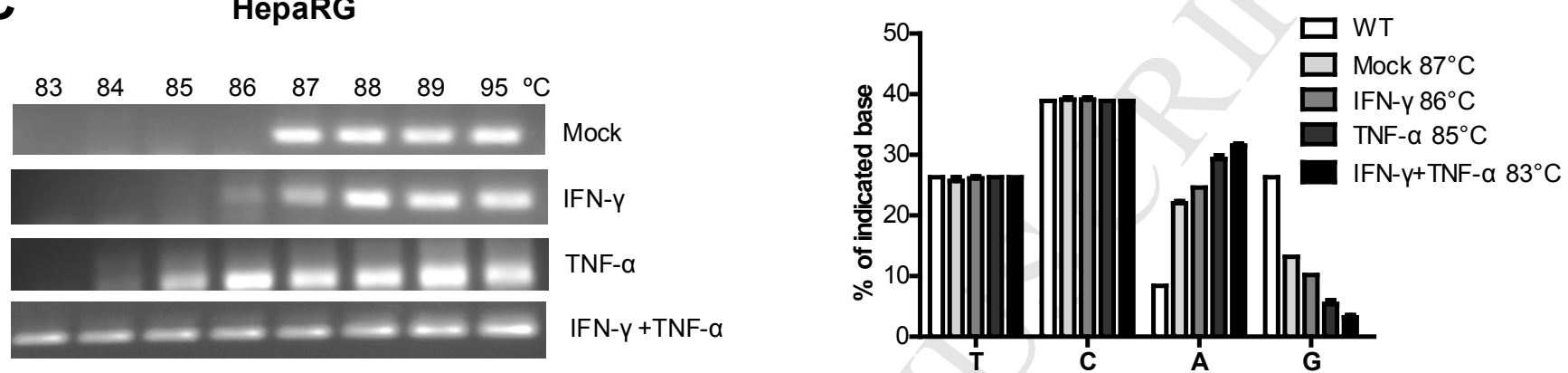

D

PHH

$\begin{array}{lllllllll}82 & 83 & 84 & 85 & 86 & 87 & 88 & 89 & 95^{\circ} \mathrm{C}\end{array}$

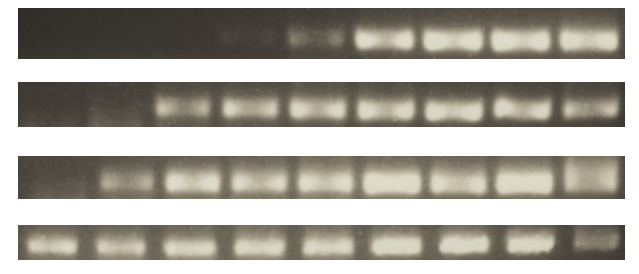

Mock

$\mathbf{E}$

A3A

IFN-Y

TNF- $\alpha$

$\mathrm{IFN}-\mathrm{\gamma}+\mathrm{TNF}-\mathrm{a}$
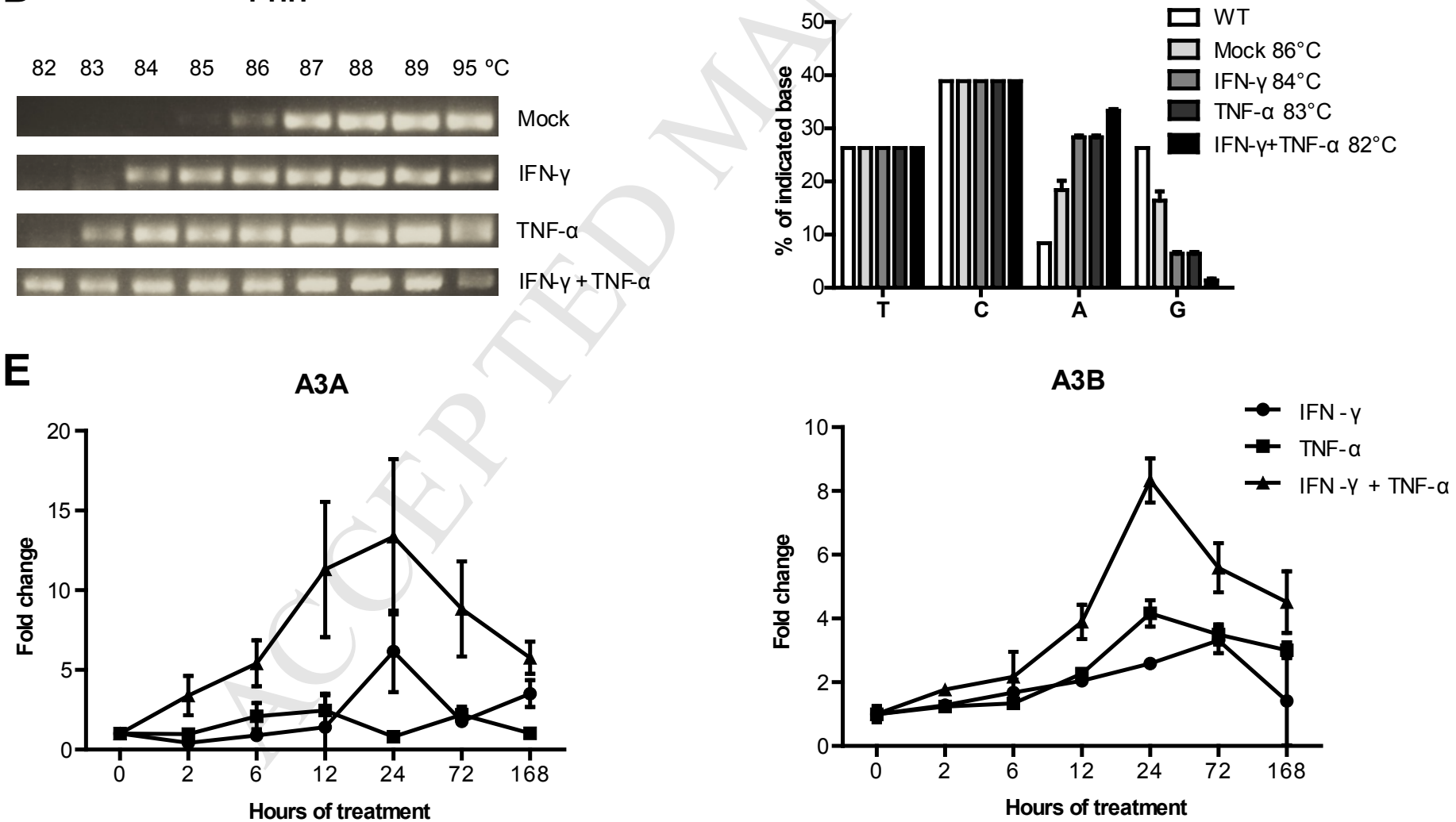

Figure S7: Additive effect of IFN- $\gamma$ and TNF- $\alpha$ treatment.

(A) HBV infected dHepaRG cells or(B) PHH were treated with $200 \mathrm{IU} / \mathrm{ml}$ IFN- $\gamma, 800 \mathrm{IU} / \mathrm{ml}$ TNF- $\alpha$ or both. HBV cccDNA relative to PRNP was analyzed by qPCR, and HBeAg in the supernatant was quantified by ELISA. (C,D) 3D-PCR was performed on cccDNA. (E) Kinetics of $A 3 A$ and $A 3 B$ expression were analyzed by qRT-PCR. 

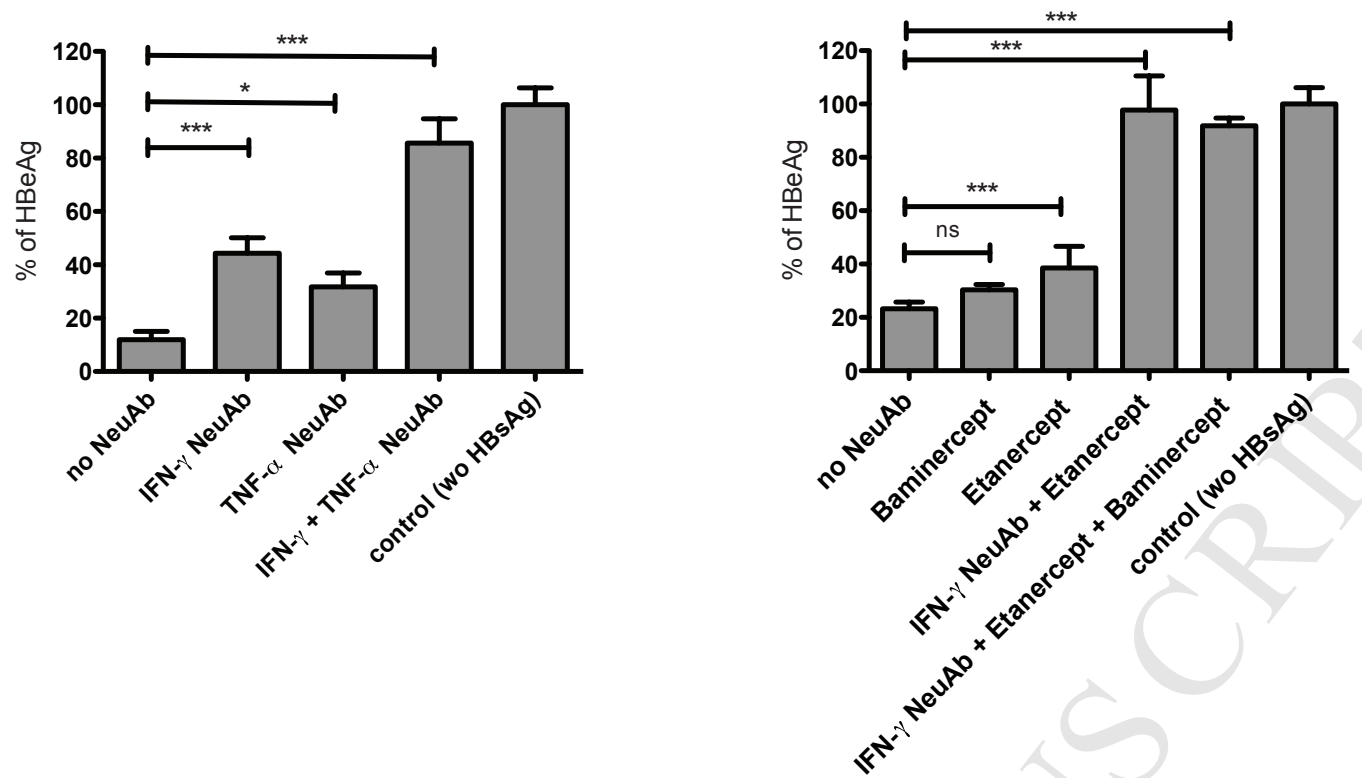

Figure S8: Neutralization of cytokines.

HBV infected dHepaRG cells were cultured in lower wells of a Transwell culture system. S-CAR-grafted T cells were cultured separately in the upper chamber and stimulated with coated HBsAg. Neutralizing antibodies were added to neutralize IFN- $y$ and TNF- $\alpha$ (left panel) and additionally lymphotoxin receptor signaling (right panel). HBeAg was determined by ELISA. 